Bài báo khoa học

\title{
Dự báo chất lượng nước mặt vùng bò̀ thành phố Hồ Chí Minh đến năm 2030 phục vụ đánh giá khả năng tiếp nhận nước thải
}

\section{Lê Ngọc Tuấn ${ }^{1 *}$, Trần Tuấn Hoàng²}

${ }^{1}$ Trường Đại học Khoa học Tự nhiên-ĐHQG-TPHCM; lntuan@hcmus.edu.vn

${ }^{2}$ Phân viện Khoa học Khí tượng Thuỷ văn và Biến đổi Khí hậu; hoangkttv@gmail.com

*Tác giả liên hệ: Intuan@hcmus.edu.vn; Tel.: +84-008371379

Ban Biên tập nhận bài: 12/4/2020; Ngày phản biện xong: 26/5/2021; Ngày đăng bài: $25 / 7 / 2021$

Tóm tắt: Nghiên cứu nhằm đánh giá chất lượng nước (CLN) vùng bờ thành phố Hồ Chí Minh (TpHCM) đến năm 2030 (thông qua $\mathrm{BOD}, \mathrm{DO}, \mathrm{NO}_{3}{ }^{-}-\mathrm{N}, \mathrm{NH}_{4}{ }^{+}-\mathrm{N}, \mathrm{PO}_{4}{ }^{3-}-\mathrm{P}, \mathrm{TSS}$ và Coliform) trong bối cảnh nước biển dâng (RCP4.5 và RCP8.5) theo các kịch bản xử lý nước thải (XLNT) khác nhau. Giai đoạn 2019-2030, nếu không cải thiện tình hình XLNT, các khu vực (và thông số ô nhiễm) đáng quan tâm gồm sông Soài Rạp, Lòng Tàu, Vàm Sát (TSS, $\mathrm{BOD}, \mathrm{PO}_{4}{ }^{3-}-\mathrm{P}$ vượt chuẩn nhiều lần), vùng ven bờ Long Hoà-Cần Thạnh (TSS, $\mathrm{PO}_{4}{ }^{3-}-\mathrm{P}$ ); khác với các vịnh và phạm vi cách bờ $3-6$ hải lý có CLN tương đối tốt (ngoại trừ TSS, 2,5-3,5 lần quy chuẩn). Trong trường hợp đáp ứng hoặc đáp ứng tối đa các quy định về XLNT, CLN vùng bờ chuyển biến tích cực (BOD và $\left.\mathrm{PO}_{4}{ }^{3-}-\mathrm{P}\right)$ trong giai đoạn 2020 2025 nhưng giảm dần vào các nnăm sau đó do gia tăng xả thải từ các hoạt động dân sinh, kinh tế. Cần lưu ý rằng, ngay cả đáp ứng tối đa về XLNT, nước mặt lục địa (thượng nguồn) vẫn có nguy cơ ô nhiê̂m với $\mathrm{BOD}, \mathrm{PO}_{4}{ }^{3-}-\mathrm{P}$, TSS có thể tương đương $2-5$ lần quy chuẩn vào năm 2030. Kết quả nghiên cứu cũng chỉ ra nguồn thải nội vi đóng góp đáng kể $\mathrm{BOD}$ và $\mathrm{PO}_{4}{ }^{3-}-\mathrm{P}$ vào $\mathrm{CLN}$ vùng bờ, đồng thời khuyến nghị giảm số kịch bản $\mathrm{RCP}$ khi mô phỏng CLN ở tương lai gần do khác biệt giữa các trường hợp tương đối nhỏ.

Từ khoá: Nước mặt; Chất lượng nước; Chỉ số chất lượng nước; Vùng bờ.

\section{1. Đặt vấn đề}

Tài nguyên nước đóng vai trò quan trọng trong mối quan hệ với sự sống và các hoạt động phát triển kinh tế-xã hội $(\mathrm{KT}-\mathrm{XH})$. Tuy nhiên, quá trình khai thác và sử dụng đã tạo nên nhiều thách thức, đặc biệt đối với khía cạnh chất lượng nước (CLN) [1]. Theo đó, ngoài kiểm soát hiệu quả nguồn thải, giám sát chất lượng nguồn tiếp nhận, việc đánh giá, dự báo diễn biến CLN đóng vai trò quan trọng, cung cấp cơ sở hoạch định và thực thi các giải pháp quản lý có liên quan. Có nhiều phương pháp được sử dụng để đánh giá CLN: phương pháp mô hình hóa, như WASP [2-3], AQUATOX [4], DELFT3D [5], HEC-RAS, QUAL2K hay MIKE [6-7]; phương pháp quan trắc môi trường; phương pháp đánh giá tổng hợp CLN theo chỉ số CLN (WQI) [8-10]. Nhìn chung, tùy vào mục tiêu và quy mô nghiên cứu, các phương pháp nghiên cứu được lựa chọn sử dụng đơn lẻ hoặc kết hợp, phổ biến là bộ phần mềm thương mại hóa MIKE.

Lưu vực Sài Gòn-Đồng Nai là lưu vực chính thuộc vùng hạ lưu hệ thống sông Đồng Nai, đóng vai trò quan trọng trong phát triển $\mathrm{KT}-\mathrm{XH}$, bao gồm sông Sài Gòn nhập lưu sông Đồng Nai tạo thành sông Nhà Bè (huyện Nhà Bè), sau đó chia thành sông Lòng Tàu (tả ngạn) và sông Soài Rạp (hữu ngạn) nhận nước sông Vàm Cỏ rồi đổ vào vịnh Đồng Tranh cùng với sông Đồng Tranh (nối các sông rạch nhỏ phía tây huyện Cần Giờ). Sông Lòng Tàu và các sông Gò Gia, Thị Vải, sông 
Thêu, Cái Mép phía đông huyện Cần Giờ đổ vào vịnh Gành Rái. Nhiều nghiên cứu về CLN đã thực hiện tại lưu vực này nhưng chủ yếu trên các sông chính [11-12], chưa chi tiết và toàn diện trong mối quan hệ với dân số, kinh tế, bối cảnh biến đổi khí hậu (BĐKH) và nước biển dâng (NBD) ở phạm vi vùng bờ.

Cùng với sự phát triển mạnh mẽ của kinh tế và dân sinh là sức ép hữu hình đến môi trường và CLN các thủy vực nhạy cảm, đặc biệt là vùng bờ TpHCM bởi tiếp nhận gần như toàn bộ nước thải dọc theo lưu vực sông Sài Gòn. Do vậy, bên cạnh công tác quan trắc, đánh giá hiện trạng CLN, việc tính toán, dự báo CLN có xét đến BĐKH và các kịch bản XLNT đóng vai trò quan trọng, hỗ trợ tích cực cho việc đánh giá khả năng tiếp nhận nước thải, cung cấp dữ liệu môi trường cần thiết phục vụ quy hoạch phát triển vùng bờ TpHCM đến năm 2030.

\section{Phương pháp nghiên cứu}

Phạm vi đánh giá chất lượng nguồn nước là vùng bờ TpHCM, bao gồm toàn bộ diện tích đất liền của huyện Cần Giờ và vùng biển ven bờ có ranh giới ngoài cách mép bờ 6 hải lý (khoảng 11 $\mathrm{km}$ ) từ vịnh Gành Rái đến cửa Soài Rạp. Phạm vi thời gian: xét mùa khô, đến 2025-2030.

\subsection{Phưong pháp khảo sát, đo đạc, lấy mẫu nước mặt}

Các thông tin đo đạc, lấy mẫu nước phục vụ nghiên cứu được tổng hợp ở Bảng 1.

Bảng 1. Thông tin về hoạt động khảo sát, đo đạc, lấy mẫu nước.

\begin{tabular}{|c|c|c|c|c|c|}
\hline Nội dung & Mục đích & Mô tả & Số mẫu & Thời gian & Thông số \\
\hline \multirow[t]{3}{*}{$\begin{array}{l}\text { Lấy mẫu } \\
\text { nước mặt }\end{array}$} & $\begin{array}{l}\text { Vị trí biên (Nhà Bè, Tân } \\
\text { Thành, Vũng Tàu) (Hình 1) }\end{array}$ & $\begin{array}{l}3 \text { vị trí * } 1 \text { mẫu/h * } \\
24 \text { h/ngđ * } 2 \text { ngđ }\end{array}$ & 144 & $\begin{array}{c}20-22 \\
\mathrm{~T} 4 / 2019\end{array}$ & \multirow{3}{*}{$\begin{array}{c}\text { Nhiệt độ, pH, } \\
\mathrm{DO}, \mathrm{BOD}, \mathrm{SS}, \\
\mathrm{NH}_{4}^{+}-\mathrm{N}, \mathrm{NO}_{3}{ }^{-}- \\
\mathrm{N}^{+} \mathrm{PO}_{4}{ }^{3-}-\mathrm{P} \\
\text { Coliform }\end{array}$} \\
\hline & $\begin{array}{l}\text { Hiệu chỉnh-kiểm định (HC- } \\
\text { KĐ) tại trạm Vàm Cỏ, Đồng } \\
\text { Tranh, Ngã 7, Cái Mép }\end{array}$ & $\begin{array}{l}4 \text { vị trí * } 1 \text { mẫu/h * } \\
24 \mathrm{~h} / \text { ngđ }\end{array}$ & 96 & $\begin{array}{c}20-21 \\
\mathrm{~T} 4 / 2019\end{array}$ & \\
\hline & $\begin{array}{l}\text { CLN vùng vịnh và vùng biển } \\
\text { ven bờ (Hình } 2 \text { ) }\end{array}$ & 15 vị trí * 2 ngđ & 30 & $\begin{array}{l}14 \text { và } 21 \\
\mathrm{~T} 4 / 2019\end{array}$ & \\
\hline \multirow[t]{2}{*}{$\begin{array}{l}\text { Đo thuỷ } \\
\text { hải văn }\end{array}$} & Trạm cửa Soài Rạp & 1 lần/h * 24 h/ngđ & 49 & $\begin{array}{c}20-21 \\
\mathrm{~T} 4 / 2019\end{array}$ & $\mathrm{H}(\mathrm{cm}), \mathrm{Q}\left(\mathrm{m}^{3} / \mathrm{s}\right)$ \\
\hline & Trạm Vũng Tàu, Tân Thành & $\begin{array}{l}1 \text { lần } / \mathrm{h} * 24 \text { h/ngđ } \\
* 2 \text { ngđ }\end{array}$ & 98 & $\begin{array}{c}20-21 \\
\mathrm{~T} 4 / 2019\end{array}$ & $\begin{array}{l}\text { Nhiệt độ, độ mặn, } \\
\text { mực nước, sóng, } \\
\text { vận tốc có hướng }\end{array}$ \\
\hline
\end{tabular}

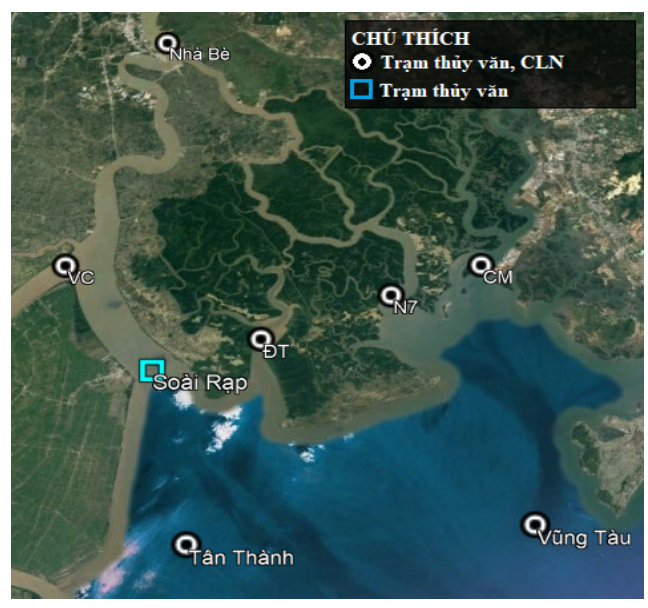

Hình 1. Vị trí các biên, hiệu chỉnh-kiểm định chất lượng nước.

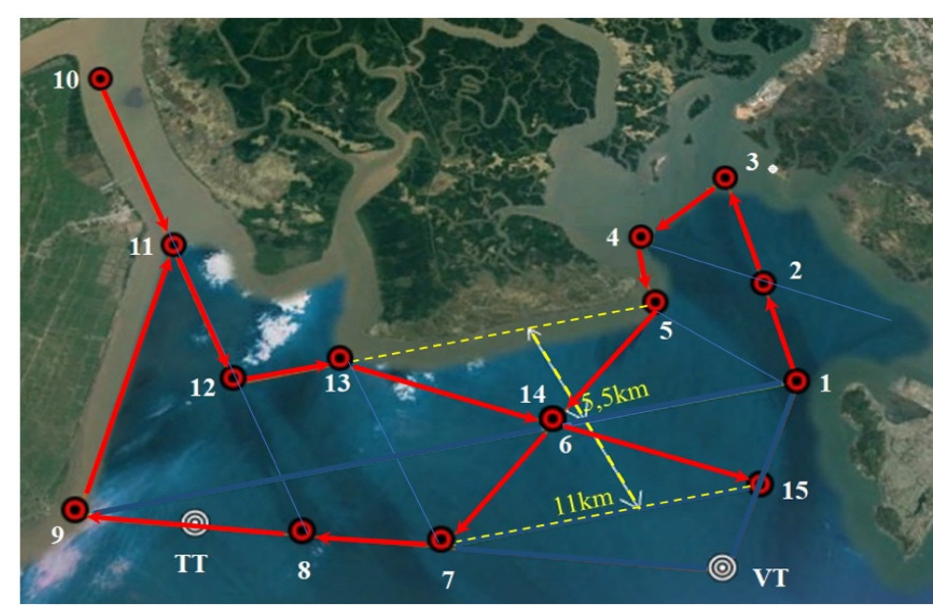

Hình 2. Vị trí lấy mẫu tại các vịnh và khu vực ven biển. 


\subsection{Phưong pháp tính toán chỉ số CLN theo mô hình WQI-CCME}

Để đánh giá tổng hợp xu thế biến đổi CLN (BOD, DO, TSS, $\mathrm{NO}_{3}{ }^{-}-\mathrm{N}, \mathrm{NH}_{4}{ }^{+}-\mathrm{N}, \mathrm{PO}_{4}{ }^{3-}-\mathrm{P}$, Coliform) trên toàn phạm vi nghiên cứu đến 2030, áp dụng chỉ số WQI-CCME được đề xuất bởi Hội đồng Bộ trưởng Môi trường Canada (Canadian Council of Ministers of Environment). Bảng 2 trình bày thang điểm CCME phục vụ phân loại CLN nguồn tiếp nhận.

$$
\mathrm{CCME}=100-\left(\frac{\sqrt{\mathrm{F}_{1}^{2}+\mathrm{F}_{2}^{2}+\mathrm{F}_{3}^{2}}}{1.732}\right)
$$

Trong đó F1 (phạm vi) là tỉ lệ giữa số thông số CLN không đạt chuẩn với tổng số các thông số được quan trắc; F2 (tần số) là số lần không đạt chuẩn với tổng số các kết quả quan trắc của tất cả các thông số; F3 (biên độ) là độ lớn của thông số không đạt chuẩn so với giá trị quy chuẩn của thông số đó; 1,732 là độ dài cực đại của vectơ tổ hợp giữa $\mathrm{F} 1, \mathrm{~F} 2$ và $\mathrm{F} 3$.

Bảng 2. Thang điểm CCME phục vụ phân loại CLN nguồn tiếp nhận.

\begin{tabular}{cll}
\hline CCME & Chất lương & Mô tả \\
\hline $\mathbf{9 5}-\mathbf{1 0 0}$ & Rất tốt & Không có mối đe dọa hoặc suy yếu về nguồn nước \\
\hline $80-94$ & Tốt & Nguồn nước được bảo vệ tương đối tốt \\
\hline $65-79$ & Trung bình & Nguồn nước đôi khi bị đe dọa hoặc suy yếu \\
\hline $45-64$ & Kém & Nguồn nước thường xuyên bị đe dọa hoặc suy yếu \\
\hline $0-44$ & Ô nhiễm nặng & Nguồn nước đang bị đe dọa hoặc suy yếu \\
\hline
\end{tabular}

\subsection{Phương pháp mô hình hóa}

\subsubsection{Dữ liệu và quy trình tính toán}

Quy trình tính toán, mô phỏng CLN được trình bày ở Hình 3.

(a) Tài liệu địa hình

Mặt cắt ngang lòng sông Sài Gòn và hệ thống kênh rạch chính trên địa bàn huyện Cần Giờ do Tổng cục Khí tượng Thuỷ văn (cũ) - nay là Bộ TN\&MT đo đạc năm 2003; đồng thời kế thừa từ các đề tài, dự án khác để cập nhập, bổ sung vào mạng lưới tính toán.

Mạng lưới sông và các mặt cắt ngang sông được biên tập và minh hoạ ở Hình $5 \mathrm{a}$ ab. Để mô phỏng tương tác dòng chảy vùng cửa sông, mô hình MIKE 21FM được thiết lập giới hạn trong khu vực có kinh độ từ $652733 \mathrm{~m}-775146 \mathrm{~m}$ và vĩ độ từ $1126543 \mathrm{~m}-1187750 \mathrm{~m}$. Dữ liệu địa hình sau khi nhập vào mô hình được xác định biên và chia lưới tính (lưới phi cấu trúc) với 7631 phần tử và 5342 nút lưới (Hình $5 \mathrm{c}$ ). Biên cứng là đường bờ, biên lỏng là phần cửa vịnh tiếp giáp với vùng biển Vũng Tàu (Hình $5 \mathrm{~d}, 5 \mathrm{e})$.

(b) Tài liệu thủy văn đối với mô hình Mike Nam và mô hình thủy lực một chiều Mike 11

Bộ số liệu do Đài Khí tượng Thủy văn khu vực Nam Bộ đo đạc năm 2019 được sử dụng làm các điều kiện biên. Biên thượng nguồn $(\mathrm{Q} \sim \mathrm{t})$ là lưu lượng xả tại hồ Dầu Tiếng và hồ Trị An (trung bình ngày). Biên hạ nguồn $(\mathrm{H} \sim \mathrm{t})$ là mực nước tại trạm Vũng Tàu và Tân An (mực nước giờ).

Bộ số liệu tính toán, HC-KĐ mô hình: sử dụng số liệu đo đạc mực nước và vận tốc tại các trạm Phú An, Tam Thôn Hiệp, Cửa Đồng Tranh và Cửa Ngã Bảy từ 29-31/03/2017 để hiệu chỉnh và từ $3-5 / 03 / 2018$ để kiểm định mô hình.

(c) Tài liệu thủy văn đối với mô hình thủy lực hai chiều Mike 21

Sau khi HC-KĐ, tính toán mô hình MIKE 11HD trong điều kiện mùa khô, tiến hành xuất kết quả lưu lượng, mực nước làm biên đầu vào cho mô hình MIKE 21HD. Sử dụng dao 
động mực nước tại biên lỏng Nhà Bè và Vàm Cỏ; sử dụng lưu lượng tại biên lỏng Thị Vải; sử dụng mực nước giờ Vàm Kênh-Vũng Tàu tại biên lỏng Vũng Tàu.

Bộ số liệu tính toán, $\mathrm{HC}-\mathrm{KĐ}$ mô hình: sử dụng số liệu đo đạc mực nước và vận tốc tại các trạm Nhà Bè, Ngã Bảy và Vàm Cỏ vào 29-31/03/2017 để hiệu chỉnh và 20-22/04/2019 để kiểm định mô hình.

(d) Tài liệu kịch bản BĐKH

Kế thừa kịch bản biến đổi nhiệt độ, lượng mưa, mực nước năm 2025 và 2030 (RCP4.5, RCP8.5) so với giai đoạn 1986-2005: mức tăng nhiệt độ giữa các kịch bản khá đồng đều, dao động $0,45-0,8^{\circ} \mathrm{C}$ [13]; mức tăng lượng mưa chênh lệch không đáng kể, khoảng 7,610,4\% [14]; mực NBD đến năm 2030 khoảng $12 \mathrm{~cm}$ trong tất cả các kịch bản [15].

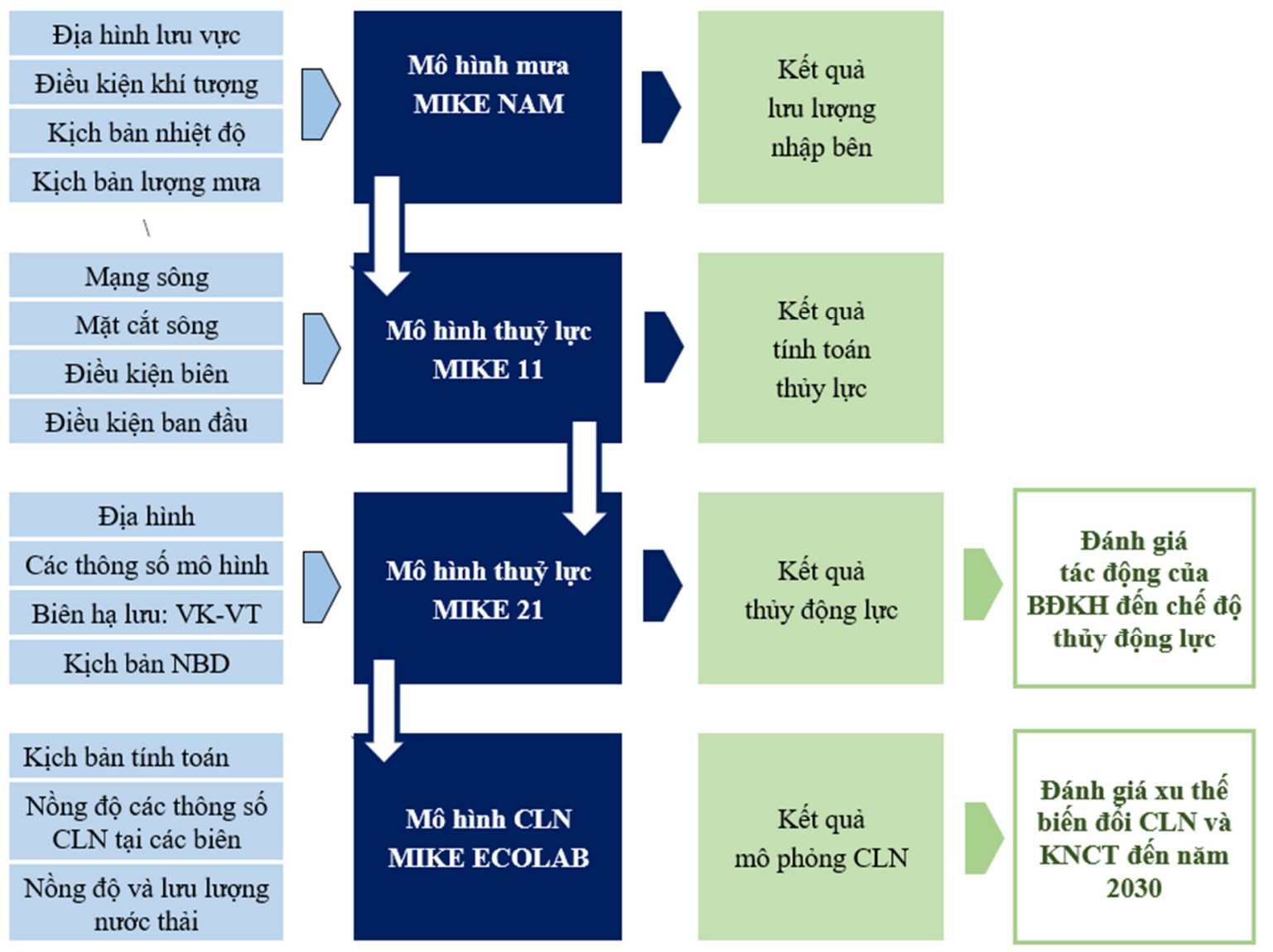

Hình 3. Quy trình tính toán chất lượng nước bằng phương pháp mô hình hóa.

\section{(e) Tài liệu về chất lượng nước}

Nguồn thải nội vi vùng bờ hiện phân thành 76 điểm thải chính, tập trung trên sông Nhà Bè, Soài Rạp, Lòng Tàu và Cái Mép. Để đánh giá CLN nguồn tiếp nhận trong mối quan hệ với XLNT và quản lý nguồn thải tại địa phương, các kịch bản phát thải được xây dựng bao gồm: Phát thải cao - TH1 (XLNT trong tương lai không thay đổi so với hiện trạng); Phát thải trung bình -TH2 (XLNT đáp ứng các quy chuẩn xả thải tương ứng và mục tiêu CLN của nguồn tiếp nhận, hướng đến mục tiêu phát triển bền vững); Phát thải thấp -TH3 (XLNT đáp ứng tối đa/ đạt mức cao nhất các quy chuẩn xả thải tương ứng nhằm tối ưu hoá chất lượng nguồn nước, tạo động lực quản lý môi trường tại địa phương). Tải lượng một số chất ô nhiễm trong nước thải tại vùng bờ TpHCM ước tính đến năm 2030 được thể hiện ở Hình 4 và Bảng 3. (Chi tiết dữ liệu không được đề cập trong bài báo này).

Các quy chuẩn tham chiếu: QCVN 08:2015/BTNMT về chất lượng nước mặt lục địa (áp dụng cột B1-mục đích tưới tiêu, thuỷ lợi); QCVN 10:2015/BTNMT về chất lượng nước biển 
(áp dụng cho vùng nuôi trồng thuỷ sản, bảo tồn thuỷ sinh ven bờ); QCVN 11:2015/BTNMT về nước thải chế biến thủy sản; QCVN 14:2015/BTNMT về nước thải sinh hoạt; QCVN 40:2011/BTNMT về nước thải công nghiệp; QCVN 62:2016/BTNMT về nước thải chăn nuôi; QCVN 02-19:2014/BNNPTNT về cơ sở nuôi tôm nước lợ - điều kiện bảo đảm vệ sinh thú $\mathrm{y}$, bảo vệ môi trường và an toàn thực phẩm; QCVN 01-79:2011/BNNPTNT về cơ sở chăn nuôi gia súc, gia cầm-quy trình kiểm tra, đánh giá điều kiện vệ sinh thú $\mathrm{y}$.

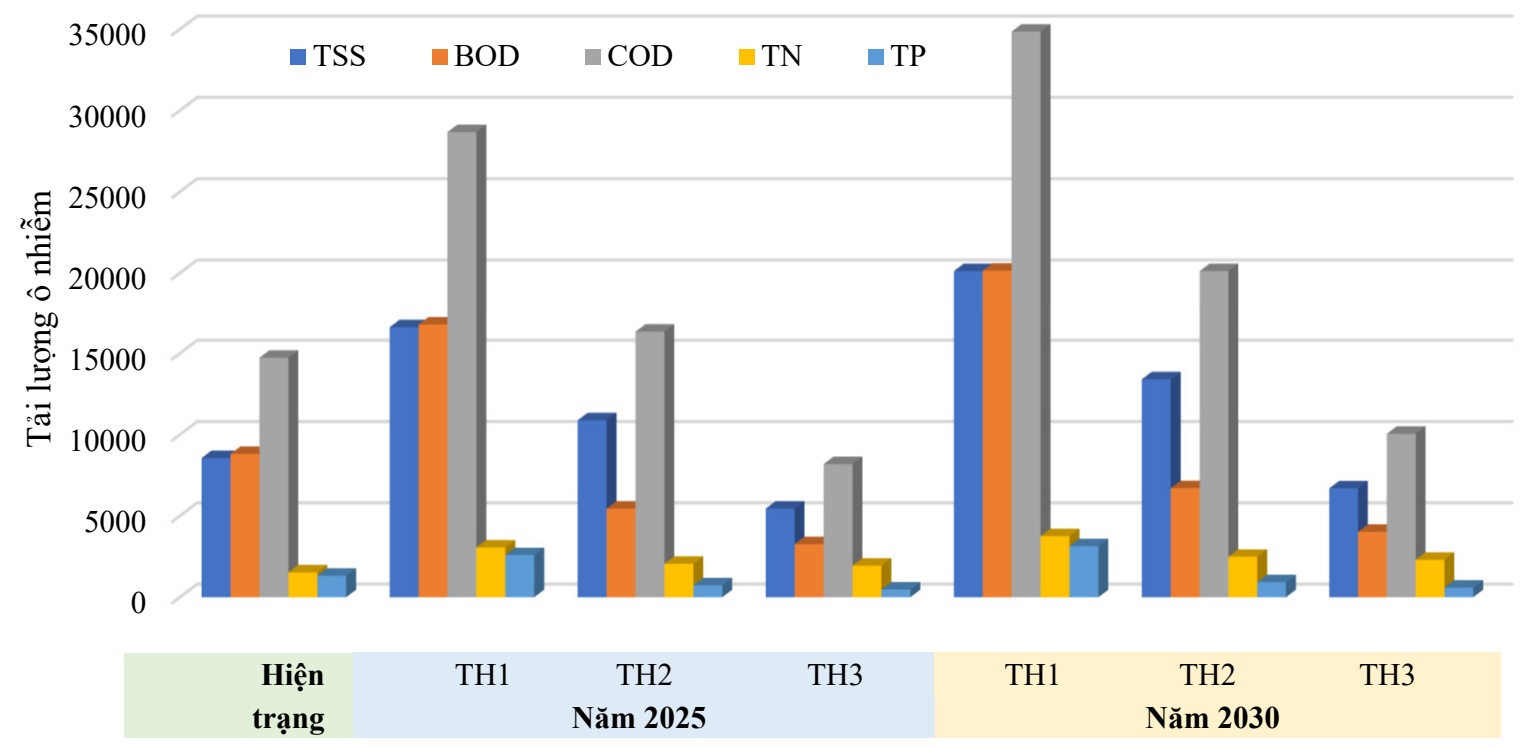

Hình 4. Tải lượng ô nhiễm trong nước thải phát sinh tại vùng bờ TpHCM đến năm 2030.

Bảng 3. Tải lượng ô nhiễm phân theo lọai nguồn thải (tấn).

\begin{tabular}{|c|c|c|c|c|c|c|c|c|c|c|}
\hline \multirow{2}{*}{ Nguồn thải } & \multicolumn{5}{|c|}{ Hiện trạng } & \multicolumn{5}{|c|}{ Năm 2030 - TH1 } \\
\hline & TSS & BOD & COD & $\mathbf{T N}$ & TP & TSS & BOD & COD & $\mathbf{T N}$ & TP \\
\hline Sinh hoạt & 466,7 & 353,4 & 919,8 & 81,6 & 74,3 & $2.612,0$ & $1.978,0$ & $5.147,8$ & 456,5 & 415,9 \\
\hline Du lịch & 22,1 & 16,8 & 43,6 & 3,9 & 3,5 & 87,2 & 66,1 & 171,9 & 15,2 & 13,9 \\
\hline Công nghiệp & 6,6 & 7,2 & 10,4 & 8,9 & 1,1 & 182,0 & 200,8 & 288,7 & 247,3 & 30,1 \\
\hline Chăn nuôi & 210,2 & 336,4 & 504,6 & 56,1 & 21,0 & 219,0 & 350,4 & 525,6 & 58,4 & 21,9 \\
\hline Thủy sản & $7.854,0$ & $8.099,5$ & $13.253,7$ & $1.374,5$ & $1.227,2$ & $17.017,0$ & $17.548,7$ & $28.716,1$ & $2.978,0$ & $2.658,9$ \\
\hline Tổng cộng & $\mathbf{8 . 5 5 9 , 7}$ & $8.813,3$ & $14.732,1$ & $1.524,9$ & $1.327,1$ & $20.117,2$ & $20.144,0$ & $34.850,2$ & $3.755,4$ & $3.140,7$ \\
\hline
\end{tabular}

Ghi chú: TN và TP lần lượt là Tổng Nito và Tổng Photpho

Sau khi HC-KĐ, tính toán MIKE 21HD trong điều kiện mùa khô (tháng 4), tiến hành mô phỏng các thông số CLN bằng môđun MIKE 21ECOLAB tương ứng với các 02 kịch bản $\mathrm{BĐKH} \mathrm{(RCP4.5} \mathrm{và} \mathrm{RCP8.5)} \mathrm{và} 03$ kịch bản XLNT đã thiết lập.

Trên cơ sở số liệu thực đo, điều kiện ban đầu của BOD, DO, TSS, $\mathrm{NO}_{3}{ }^{-}-\mathrm{N}, \mathrm{NH}_{4}{ }^{+}-\mathrm{N}$, $\mathrm{PO}_{4}{ }^{3-}-\mathrm{P}$, Coliform, nhiệt độ, độ muối và vận tốc gió lần lượt được gán là $4,5 \mathrm{mg} / 1,0,6 \mathrm{mg} / \mathrm{L}$, $160 \mathrm{mg} / \mathrm{L}, 0,63 \mathrm{mg} / \mathrm{L}, 0,04 \mathrm{mg} / \mathrm{L}, 0,02 \mathrm{mg} / \mathrm{L}, 1 / 100 \mathrm{~mL}, 27^{\circ} \mathrm{C}, 28$ psu và $2 \mathrm{~m} / \mathrm{s}$.

(f) Đánh giá hiệu quả mô phỏng

Hiệu quả mô phỏng thuỷ lực: Các thông số mô hình được xác định bằng cách tính toán và thử sai. Hiệu chỉnh các thông số đối với khu vực sao cho kết quả tính toán phù hợp với số liệu thực đo. Hiệu quả mô phỏng được đánh giá thông qua hệ số Nash-Sutcliffe (NSE) và $\mathrm{R}^{2}$, đạt mức khá và tốt khi NSE và $\mathrm{R}^{2}$ lần lượt trong khoảng $0,65-0,85$ và trên 0,85 .

Hiệu quả mô phỏng CLN: được đánh giá thông qua sai số giữa kết quả mô phỏng CLN và số liệu thực đo tại khu vực nghiên cứu. 


\subsubsection{Các kịch bản tính toán}

Các kịch bản mô phỏng CLN tại khu vực nghiên cứu được tóm tắt ở Bảng 4 . Các tổ hợp so sánh, đánh giá như sau:

- Biến đồi CLN theo các kịch bản $B Đ K H: K B 2$ và $K B 3 ; K B 4$ và $K B 10$

- Biến đổi CLN theo thời gian, XLNT như hiện tại: KB1-KB3-KB4; KB1-KB11

- Biến đổi CLN theo thời gian, XLNT đáp ứng các quy định: KB1-KB8-KB5

- Biến đổi CLN theo thời gian, XLNT đáp ứng tối đa các quy định: KB1-KB9-KB6

- Khả năng chi phối CLN vùng bờ của các nguồn thải nội vi: KB3 và $K B 7$; $K B 4$ và $K B 12$.

Bảng 4. Các kịch bản mô phỏng CLN tại khu vực nghiên cứu.

\begin{tabular}{|c|c|c|c|c|}
\hline Năm & Kịch bản XLNT nội vi vùng bờ & Điều kiện biên CLN Nhà Bè & КВ ВĐКН & Kí hiệu \\
\hline 2019 & Hiện trạng & Hiện trạng & - & KB1 \\
\hline \multirow[t]{5}{*}{2025} & \multirow[t]{2}{*}{ Tương tự hiện trạng } & Tăng 10\% so với hiện trạng & $\mathrm{RCP} 4.5$ & KB2 \\
\hline & & Tăng 10\% so với hiện trạng & $\mathrm{RCP} 8.5$ & KB3 \\
\hline & Đáp ứng quy chuẩn xả thải & Tăng 10\% so với hiện trạng & $\mathrm{RCP} 8.5$ & KB8 \\
\hline & Đáp ứng tối đa quy chuẩn xả thải & Tăng 10\% so với hiện trạng & RCP8.5 & KB9 \\
\hline & Không xét nguồn thải nội vi & Tăng 10\% so với hiện trạng & $\mathrm{RCP} 8.5$ & KB7 \\
\hline \multirow[t]{6}{*}{2030} & \multirow[t]{4}{*}{ Tương tự hiện trạng } & Tăng 20\% so với hiện trạng & $\mathrm{RCP} 4.5$ & $\mathrm{~KB} 10$ \\
\hline & & Tăng 20\% so với hiện trạng & $\mathrm{RCP8.5}$ & KB4 \\
\hline & & Tăng 30\% so với hiện trạng & $\mathrm{RCP} 8.5$ & KB11 \\
\hline & & Tương tự hiện trạng & RCP8.5 & $\mathrm{KB} 12$ \\
\hline & Đáp ứng quy chuẩn xả thải & Tăng 20\% so với hiện trạng & $\mathrm{RCP} 8.5$ & KB5 \\
\hline & Đáp ứng tối đa quy chuẩn xả thải & Tăng 20\% so với hiện trạng & RCP8.5 & KB6 \\
\hline
\end{tabular}
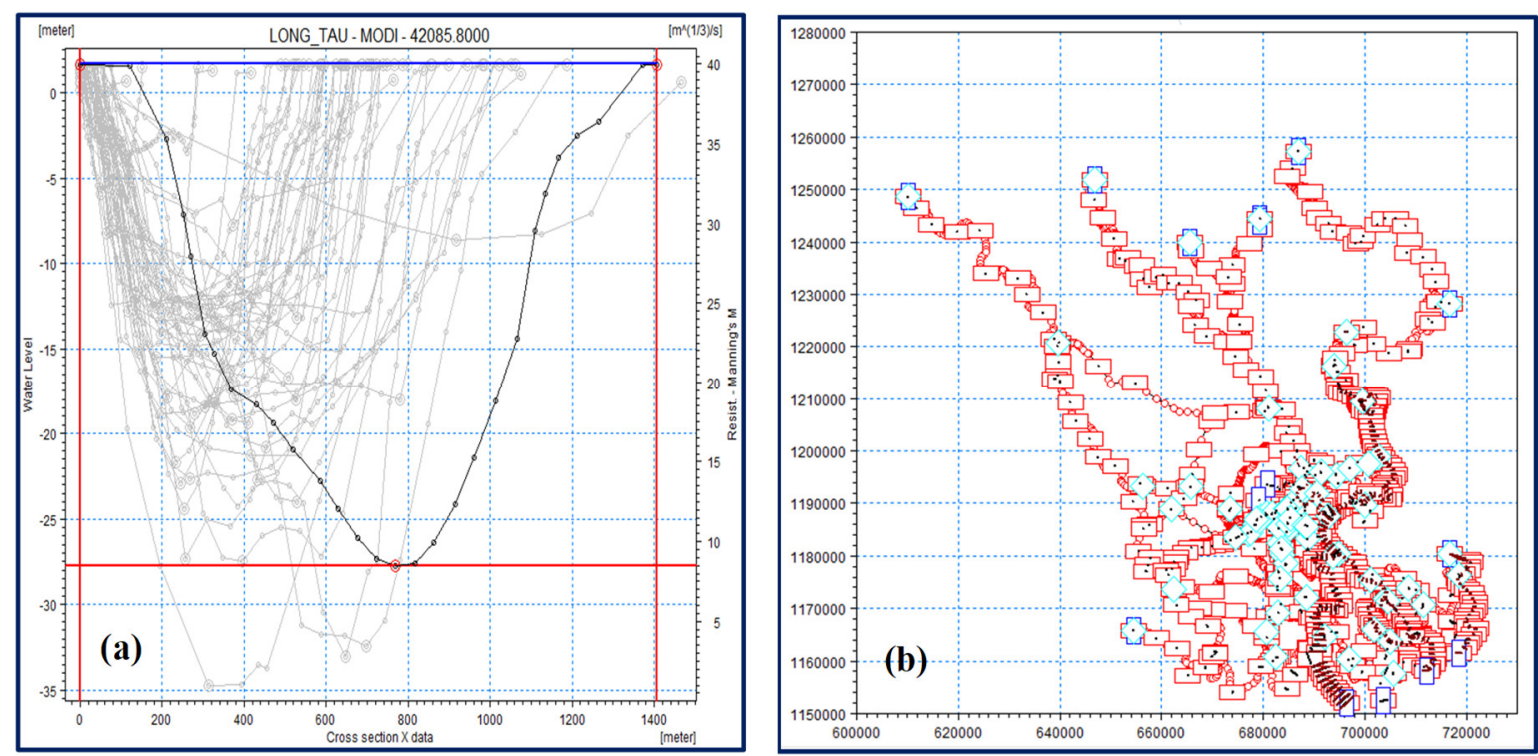

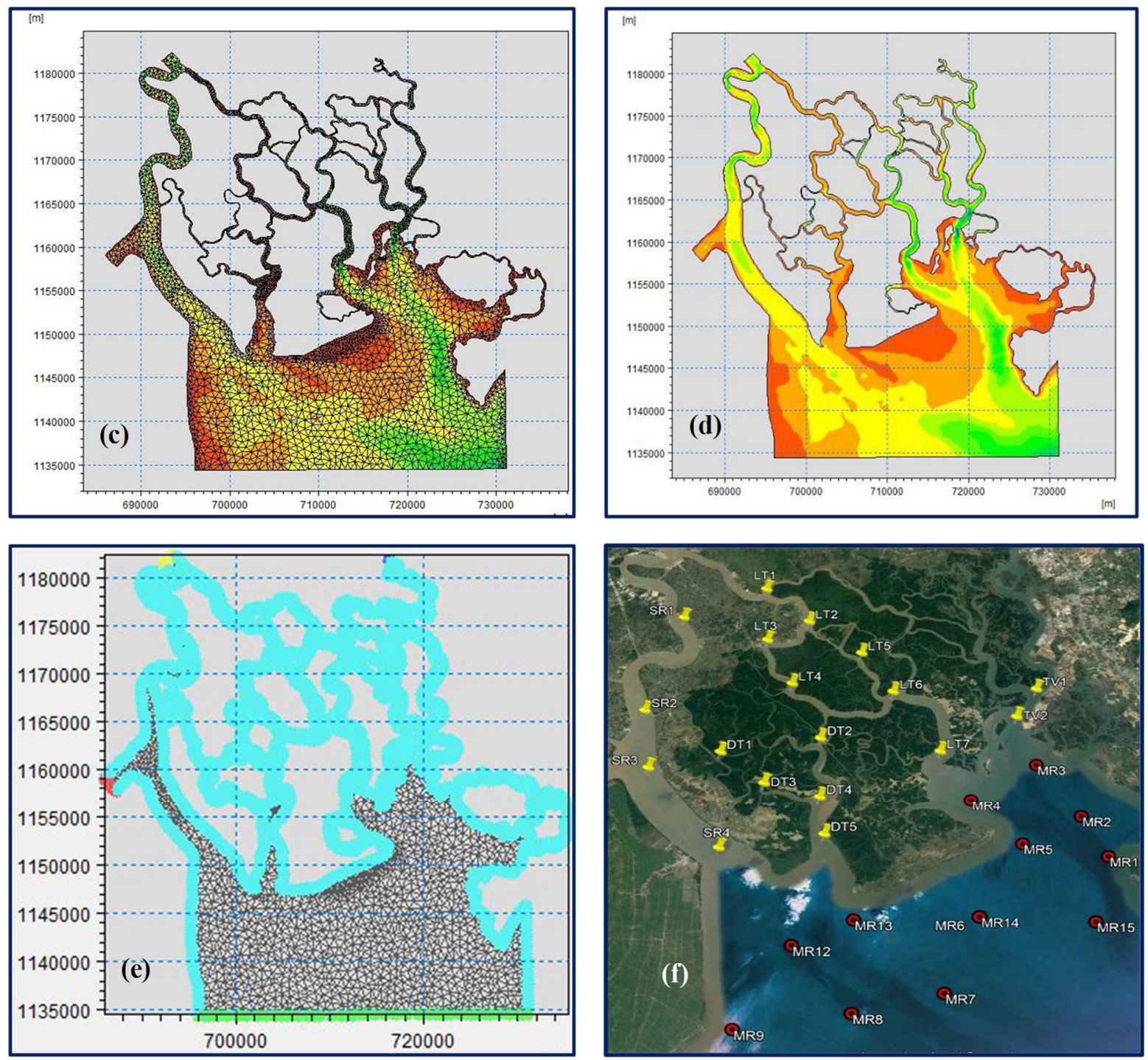

Hình 5. (a) Minh hoạ mặt cắt trên sông Lòng Tàu; (b) Mạng sông thiết lập trong Mike 11; (c) Chia lưới tam giác trong Mike 21FM; (d) Địa hình đáy cho mô hình Mike 21; (e) Biên tính toán trong Mike $21 \mathrm{HD}$; (f) Các vị trí đại diện CLN vùng bờ TpHCM.

\section{Kết quả nghiên cứu}

\subsection{Kết quả hiệu chỉnh-kiểm định các mô hình tính toán}

MIKE 11: Bộ hệ số nhám sau hiệu chỉnh (từ 20-60 tùy đoạn sông) phân bố giảm dần về phía hạ nguồn (do thượng nguồn có độ nhám bề mặt cao, nhiều lớp phủ thực vật và vật cản, sông có nhiều uốn khúc, quanh co...), được dùng để tính toán thủy lực phục vụ kiểm định mô hình. Bảng 5 cho thấy hệ số $\mathrm{NASH}$ và $\mathrm{R}^{2}$ khá cao $(0,90-0,99$ và $0,84-0,97$ tương ứng với $h$ và v), phản ánh kết quả tính toán và dữ liệu thực đo tương đối tương đồng, đủ tin cậy để mô phỏng thuỷ lực tại khu vực nghiên cứu đến năm 2030, có xem xét các kịch bản BĐKH, chủ đạo là kịch bản NBD.

MIKE 21: Bảng 5 cũng cho thấy kết quả tính toán phù hợp với dữ liệu thực đo, hệ số $\mathrm{R}^{2}$ ở các trạm tương đối cao $(>0,9)$, theo đó, mô hình MIKE 21 đủ tin cậy để mô phỏng chế độ thủy lực và lan truyền chất tương ứng với các kịch bản tính toán. 
Bảng 5. Hiệu quả HC-KĐ mô hình MIKE 11 và MIKE 21 đối với mực nước (h) và vận tốc (v).

\begin{tabular}{|c|c|c|c|c|c|c|c|c|c|}
\hline \multirow{3}{*}{ Mô hình } & \multirow{3}{*}{ Trạm } & \multicolumn{4}{|c|}{ Hiệu chỉnh } & \multicolumn{4}{|c|}{ Kiểm định } \\
\hline & & \multicolumn{2}{|c|}{ NASH } & \multicolumn{2}{|c|}{$\mathbf{R}^{2}$} & \multicolumn{2}{|c|}{ NASH } & \multicolumn{2}{|c|}{$\mathbf{R}^{2}$} \\
\hline & & $h$ & $\boldsymbol{v}$ & $h$ & $\boldsymbol{v}$ & $h$ & $v$ & $h$ & $v$ \\
\hline \multirow{4}{*}{ MIKE 11} & Phú An & 0,96 & 0,96 & 0,99 & 0,97 & 0,90 & 0,96 & 0,97 & 0,96 \\
\hline & Tam Thôn Hiệp & 0,97 & 0,91 & 0,99 & 0,91 & 0,97 & 0,89 & 0,98 & 0,93 \\
\hline & Đồng Tranh & 0,98 & 0,87 & 0,99 & 0,87 & 0,96 & 0,88 & 0,97 & 0,89 \\
\hline & Ngã Bảy & 0,98 & 0,87 & 0,99 & 0,90 & 0,95 & 0,84 & 0,97 & 0,87 \\
\hline \multirow[t]{3}{*}{ MIKE 21} & Nhà Bè & - & - & 0,99 & 0,94 & - & - & 0,98 & 0,93 \\
\hline & Vàm Cỏ & - & - & 0,98 & 0,93 & - & - & 0,98 & 0,91 \\
\hline & Ngã Bảy & - & - & 0,96 & 0,93 & - & - & 0,96 & 0,95 \\
\hline
\end{tabular}

Mô hình CLN: Hiệu quả mô phỏng CLN phụ thuộc nhiều yếu tố như phân bố tải lượng ô nhiễm, độ tin cậy của kết quả quan trắc hay các quá trình phức tạp trong Modul Ecolab... Kết quả hiệu chỉnh mô hình CLN từ 21:00, 20/04/2019 đến 21:00, 21/04/2019 (Bảng 6) cho thấy:

- $\mathrm{BOD}, \mathrm{DO}, \mathrm{NO}_{3}{ }^{-}-\mathrm{N}, \mathrm{PO}_{4}{ }^{3-}-\mathrm{P}$, nhiệt, độ mặn: sai số nhỏ, kết quả mô phỏng tin cậy.

$-\mathrm{NH}_{4}{ }^{+}-\mathrm{N}$ : sai số trung bình, kết quả mô phỏng tương đối chính xác.

- TSS, Coliform: sai số tương đối lớn, độ tin cậy chấp nhận được

Bảng 6. Sai số (\%) giữa kết quả mô phỏng và giá trị thực đo các thông số CLN.

\begin{tabular}{lccccccccc}
\hline TRẠM & TSS & DO & BOD & $\mathbf{N H}_{4}{ }^{+}-\mathbf{N}$ & $\mathbf{N O}_{3}{ }^{-}-\mathbf{N}$ & $\mathbf{P O}_{4}{ }^{3-}-\mathbf{P}$ & Coliform & Nhiệt độ & Độ mặn \\
\hline Đồng Tranh & 21,1 & 1,13 & 0,22 & 0,002 & 0,18 & 0,18 & 4,2 & 2,3 & 0,63 \\
Ngã 7 & 32,3 & 1,7 & 3,8 & 17,4 & 3,6 & 3,1 & 59,6 & 1,9 & 1,3 \\
Cái Mép & 9,6 & 0,82 & 0,28 & 0,01 & 0,09 & 0,09 & 6,67 & 1,6 & 1,5 \\
\hline
\end{tabular}

\subsection{Chất lượng nước mặt đến năm 2030 theo các kịch bản BĐKH và xủ lý nước thải}

Bảng 7-8 trình bày kết quả mô phỏng các thông số CLN (BOD, DO, TSS, Coliform, $\mathrm{NH}_{4}{ }^{+}-\mathrm{N}$, $\mathrm{NO}_{3}{ }^{-}-\mathrm{N}$ và $\mathrm{PO}_{4}{ }^{3-}-\mathrm{P}$ ) và chỉ số tổng hợp $\mathrm{WQI}-\mathrm{CCME}$ đến năm 2030 có xét đến $\mathrm{NBD}$ và các kịch bản XLNT khác nhau. Các vị trí đại diện phục vụ đánh giá CLN vùng bờ TpHCM được thể hiện ở Hình 5f.

\subsubsection{Biến đổi CLN theo thời gian giả định XLNT như hiện tại: KB1-KB3-KB4; KB1-KB11}

Từ nay đến năm 2030, giả định tình hình XLNT không được cải thiện, CLN vùng bờ sẽ suy giảm dần bởi sự gia tăng tải lượng ô nhiê̂m từ nước thải của các hoạt động dân sinh, kinh tế. Bảng 8 cho thấy ở hiện trạng, CCME nước biển ven bờ là 78 (từ 47-83, chỉ $3 / 13$ vị trí ở mức trung bình và kém) và nước mặt lục địa là 59 (từ 26-83 với $8 / 16$ vị trí ở mức kém và ô nhiễm nặng). Năm 2030 , tuy CCME vùng ven biển và lục địa thay đổi không đáng kể, lần lượt đạt 75 và 51 (KB4), nhưng phạm vi suy giảm CLN mở rộng hơn, tương ứng $7 / 13$ và $11 / 16$ vị trí ở mức trung bình trở xuống.

Các thông số CLN đáng quan tâm (KB4) như TSS (hàm lượng trong nước mặt lục địa và nước biển ven bờ tương đương 3-8 lần và 2,5-3,5 lần quy chuẩn), $\mathrm{BOD}$ (khoảng $8,5-13,5$ lần, 3-13 lần và $2-10$ lần quy chuẩn lần lượt trên sông Soài Rạp, Lòng Tàu và Vàm Sát), $\mathrm{PO}_{4}{ }^{3-}-\mathrm{P}$ (khoảng $2-3$ lần quy chuẩn trong phạm vi lục địa và $2,5-3$ lần quy chuẩn tại vùng cửa sông đổ vào các vịnh) và Coliform (tương đương 4,5-6 lần trên sông Soài Rạp và Lòng Tàu). Trong đó, $\mathrm{BOD}$ và $\mathrm{PO}_{4}{ }^{3-}-\mathrm{P}$ gia tăng đáng kể so với hiện trạng, tương ứng $123 \%$ (37-216\%) và 52\% (29-75\%) trên sông Soài Rạp, $89 \%(12-145 \%)$ và $18 \%(11-25 \%)$ trên sông Lòng Tàu (Bảng 7$)$. Trong trường hợp gia tăng tải lượng ô nhiễm ngoại vi (KB11), CLN vùng bờ càng suy giảm: chuyển biến khá rõ nét (so với KB4) trong phạm vi lục địa, nhất là thượng nguồn sông Soài Rạp và Lòng Tàu, nhưng không đáng kể tại các vịnh và vùng biển ven bờ do tương tác thuỷ lực sông-biển mạnh mẽ nơi đây.

Về phân bố không gian, càng hướng ra vùng cửa sông, ven biển, sự trao đổi nước càng được tăng cường, thúc đẩy quá trình pha loãng/ khuếch tán chất ô nhiễm, theo đó, CLN dần được cải thiện (Hình 6). Chỉ số CCME giúp nhận diện các khu vực có nguy cơ ô nhiễm như sông Soài Rạp, sông 
Lòng Tàu, sông Vàm Sát (TSS, BOD, $\mathrm{PO}_{4}{ }^{3-}-\mathrm{P}$, Coliform), khu vực ven bờ Long Hoà - Cần Thạnh (TSS, $\left.\mathrm{PO}_{4}{ }^{3-}-\mathrm{P}\right)$. CLN tại vịnh Đồng Tranh, vịnh Gành Rái cũng như khu vực cách bờ 3-6 hải lý tương đối tốt, thường chịu ảnh hưởng bởi phù sa từ các cửa sông (TSS).

\subsubsection{Biến đổi CLN theo thời gian giả định XLNT đáp ứng các quy định: KB1-KB8-KB5}

Trong trường hợp kiểm soát được nước thải nội vi vùng bờ theo các quy chuẩn kỹ thuật tương thích, tải lượng ô nhiễm xả thải vào các nguồn tiếp nhận giảm đi đáng kể. Theo đó, năm 2025 so với hiện trạng (KB8 vs. KB1), một số thông số CLN có dấu hiệu chuyển biến tích cực như BOD (giảm $36-39 \%$ trên sông Soài Rạp và Lòng Tàu, nhưng vẫn vượt chuẩn), Coliform (đáp ứng quy chuẩn) hoặc gia tăng không đáng kể như TSS (luôn vượt chuẩn). Giai đoạn 2025-2030, tăng trưởng dân số và phát triển kinh tế tại vùng bờ $\mathrm{TpHCM}$ tất yếu làm gia tăng nhu cầu sử dụng nước cũng như lượng nước thải phát sinh, tác động tiêu cực đến CLN nguồn tiếp nhận. So với năm 2025 (KB8), nồng độ BOD và TSS năm 2030 (KB5) tăng 57\% (26-93\%) và 10\% (2-15\%) trên sông Soài Rạp, 33\% (28$46 \%$ ) và $7 \%(2-16 \%)$ trên sông Lòng Tàu (Hình $7 \mathrm{a}, 7 \mathrm{~b})$.

Nhìn chung, CLN cũng phân bố tăng dần về phía biển. Năm 2030, nguồn nước vùng bờ (KB5) ít nguy cơ ô nhiê̂mm hơn so với trường hợp không xem xét cải thiện hiệu quả XLNT (KB4) (cả về số lượng thông số, mức độ vượt chuẩn và phạm vi ô nhiễm): CCME vùng ven bờ và trong lục địa lần lượt là 81 và 61 , chỉ $1 / 13$ và $7 / 16$ vị trí CLN từ mức kém trở xuống. Cụ thể, sông Soài Rạp có CCME đạt 33 (từ 28-49), ô nhiễm nặng (nồng độ $\mathrm{BOD}, \mathrm{PO}_{4}{ }^{3-}-\mathrm{P}$ và TSS lần lượt tương đương 7-12,5 lần, 2-3 lần và 4-7,5 lần quy chuẩn), thông tin tương tự cho sông Lòng Tàu là 57 (từ 38-83), CLN kém đến trung bình ( $\mathrm{BOD}, \mathrm{PO}_{4}{ }^{3-}-\mathrm{P}$ và $\mathrm{TSS}$ khoảng $1,5-9,5$ lần, $2-3$ lần và $3-5,5$ lần quy chuẩn), đối với các vịnh và vùng biển ven bờ là 81 (từ 60-84), CLN tốt (TSS khoảng 2,5-4 lần quy chuẩn).

Kết quả nghiên cứu chỉ ra rằng, việc tăng cường kiểm soát nguồn thải và XLNT trong thời gian tới rất quan trọng và cấp thiết, đặc biệt trong giai đoạn 2020-2025, góp phần nâng cao tính khả thi và triển vọng quản lý hiệu quả chất lượng nước mặt vùng bờ TpHCM.

\subsubsection{Biến đổi CLN theo thời gian giả định XLNT đáp ứng tối đa các quy định: KB1-KB9-KB6}

Kết quả mô phỏng cho thấy đây là trường hợp khả quan nhất về CLN nguồn tiếp nhận. Tương tự như trên, các thông số CLN đáng quan tâm gồm $\mathrm{BOD}, \mathrm{PO}_{4}{ }^{3-}-\mathrm{P}$, TSS nhưng cải thiện đáng kể về mức độ và phạm vi ô nhiễm (Hình $7 \mathrm{c}, 7 \mathrm{~d})$. Năm 2030, so với quy chuẩn, nồng độ các thông số nêu trên (KB6) lần lượt tương đương 3-5 lần, 2-3 lần, 3,5-5 lần tại thượng nguồn sông Soài Rạp (tính đến hợp lưu với sông Vàm Cỏ), 4 lần, 1,5-2 lần, 3-5 lần trên sông Vàm Sát (gần hợp lưu với sông Soài Rạp) và 2,5-3 lần, 1,5-3,5 lần, 3-5 lần tại thượng nguồn sông Lòng Tàu (LT1-LT3, trước khi chảy qua khu vực rừng ngập mặn). CLN tại các vịnh và vùng ven biển nhìn chung khá tốt, đáp ứng quy chuẩn.

\subsubsection{Khả năng chi phối $C L N$ vùng bờ của các nguồn thải nội vi: $K B 3$ và $K B 7$; $K B 4$ và $K B 12$}

Nhằm đánh giá ảnh hưởng của nguồn thải nội vi, CLN vùng bờ năm 2025 được mô phỏng với giả định không có tải lượng ô nhiễm đóng góp từ những nguồn thải này (KB7). Kết quả cho thấy, ngoại trừ TSS (tương đương 2,5-5 lần quy chuẩn, Hình $7 \mathrm{e}, 7 \mathrm{f}$ ), 06 thông số còn lại ở KB7 đều đáp ứng quy định đối với nguồn tiếp nhận. Theo đó, $\mathrm{CCME}$ đạt mức trung bình và tốt lần lượt đối với nước mặt lục địa và nước biển ven bờ. Xem xét đồng thời với $\mathrm{KB} 3$ nêu trên, có thể thấy nguồn thải nội vi chi phối đáng kể CLN vùng bờ, nhất là khu vực lục địa (chênh lệch khá lớn giữa KB3 vs. KB7), rõ nét với BOD (trung bình 32-33 lần (dao động 12-60 lần) trên sông Soài Rạp, Lòng Tàu và $2-3$ lần trên sông Đồng Tranh) và $\mathrm{PO}_{4}{ }^{3-}-\mathrm{P}$ (số liệu tương tự là $31-35$ lần và $15,5-17,5$ lần). Nói cách khác, nguồn thải nội vi đóng góp đáng kể $\mathrm{BOD}$ và $\mathrm{PO}_{4}{ }^{3-}-\mathrm{P}$ vào $\mathrm{CLN}$ vùng bờ. Bên cạnh đó, kết quả nghiên cứu còn chỉ ra sự chuyển biến tiêu cực CLN trên toàn phạm vi vùng bờ khi gia tăng tình trạng ô nhiễm nguồn nước ngoại vi trước khi đến biên đầu vào tại trạm Nhà Bè (KB12 và KB4). (Dữ liệu KB7 và KB12 không được trình bày chi tiết trong bài báo này). 


\subsubsection{Biến đổi $C L N$ theo các kịch bản $B Đ K H: ~ K B 2$ và $K B 3 ; K B 4$ và $K B 10$}

Bảng 8 cho thấy không nhiều khác biệt về CLN giữa 02 kịch bản BĐKH (RCP4.5 và RCP8.5) tại cùng một mốc thời gian đánh giá, cũng như giữa 2 mốc thời gian liền kề (2025 và 2030) với cùng một kịch bản BĐKH. Điều này có thể giải thích thông qua sự thay đổi không đáng kể lưu lượng dòng chảy và độ cao mực nước theo sau sự ít biến đổi nhiệt độ, lượng mưa và mực nước biển trong thời đoạn nghiên cứu. Cụ thể, CLN được mô phỏng với bước nhảy 5 năm trong tổng thời gian khoảng 10 năm (tính đến 2030) là khoảng thời gian khá ngắn để những thay đổi khí hậu và NBD biểu hiện rõ nét, tức chênh lệch giữa các kịch bản $\mathrm{RCP}$ và giữa các mốc thời gian tương đối thấp (thường đáng kể ở nửa sau thế kỉ 21). Thêm vào đó, CLN được mô phỏng trong mùa khô tại vùng ven biển nên điều kiện thuỷ lực chịu chi phối chủ yếu bởi mực NBD trong bối cảnh BĐKH. Do đó, khuyến nghị chỉ xem xét 1 kịch bản BĐKH cho các mô phỏng đến năm 2030.
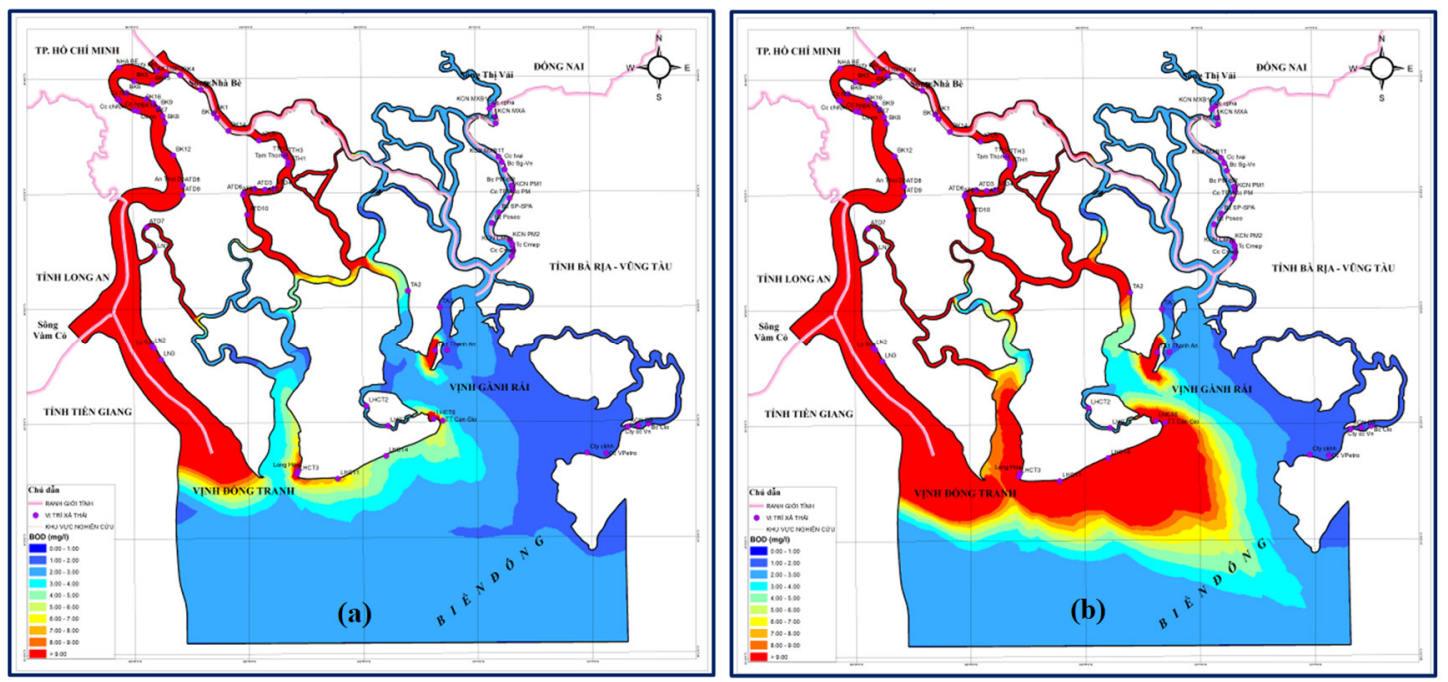

Hình 6. Biến đổi nồng độ BOD giai đoạn 2019-2030: XLNT như hiện trạng: (a) KB1 và (b) KB4.

Bảng 7. Kết quả mô phỏng CLN vùng bờ đến năm 2030 theo các kịch bản XLNT và BĐKH.

\begin{tabular}{|c|c|c|c|c|c|c|c|c|c|c|c|c|c|c|c|c|c|c|c|c|c|c|}
\hline \multirow{2}{*}{ KHU VựC } & \multirow{2}{*}{$\begin{array}{l}\text { VI! } \\
\text { TRÍ }\end{array}$} & \multicolumn{8}{|c|}{ KB1 - HIỆN TRẠNG } & \multicolumn{6}{|c|}{ KB8 - NĂM 2025} & \multicolumn{7}{|c|}{ KB11 - NĂM 2030} \\
\hline & & D & 0 & $\mathrm{NH}_{4}{ }^{+}$ & $\mathrm{NO}_{3}{ }^{-}$ & $\mathrm{PO}_{4}{ }^{2-}$ & ss & $\mathrm{C}$ & D & DO & $\mathrm{NH}_{4}{ }^{+}$ & $\mathrm{NO}_{3}$ & 3 & TSS & oli & D & DO & $\mathrm{NH}_{4}^{+}$ & +1 & $\mathrm{PO}_{4}{ }^{3 .}$ & TSS & Coliform \\
\hline \multirow{3}{*}{$\begin{array}{c}\text { Sông } \\
\text { Soài Rạp }\end{array}$} & SR1 & 196,3 & 1,0 & 3 & 0,42 & 0,99 & 312,5 & 42.000 & 153,3 & 1,1 & 0,02 & 0,26 & 0,99 & 326,7 & 3.900 & 198,9 & 1,0 & 0,0 & 0,2 & 1,0 & 399,0 & 43.000 \\
\hline & SR3 & 59,8 & 4,2 & 05 & 0,72 & 0,41 & 280,4 & 26.000 & & 4,9 & & 0,66 & 0,57 & 00,8 & 140 & 130,9 & 1,2 & 0,0 & 0,6 & $0, r$ & 27,6 & 000 \\
\hline & SR4 & 22,3 & 6,7 & 0,04 & 0,51 & 0,35 & 171,4 & 1.900 & 11,1 & 6,7 & 0,04 & 0,57 & 0,29 & 179,0 & 260 & 70,8 & 1,4 & 0,0 & 0,6 & 0,4 & 54,1 & .400 \\
\hline \multirow{3}{*}{$\begin{array}{c}\text { Sông } \\
\text { Vàm Sát }\end{array}$} & DT1 & 7,0 & 5,1 & & & 0,04 & 182,2 & 6.400 & 55,8 & 3,1 & 0,04 & 0,58 & 0,47 & 34,0 & 210 & 157,2 & 1,2 & 0,0 & 0,5 & 0,8 & 17,2 & 9.500 \\
\hline & DT3 & 2,9 & 6,9 & 0,04 & 0,59 & 0,05 & 155,4 & 280 & 4,9 & 5,9 & 0,04 & 0,58 & 0,05 & 166,1 & 210 & 35,0 & 1,8 & 0,0 & 0,6 & 2 & 16,0 & 500 \\
\hline & DT4 & 6 & 7,6 & 0,04 & 0,59 & 0,31 & 150,2 & 530 & 2,9 & 7,8 & 0,04 & 0,59 & 0,04 & 150,4 & 200 & 8,0 & 4,8 & 0,0 & 0,6 & 3 & 56,5 & 530 \\
\hline \multirow{4}{*}{$\begin{array}{l}\text { Sông } \\
\text { Đồng } \\
\text { Tranh }\end{array}$} & LT3 & 7,3 & 2,8 & 0,03 & 0,46 & 0,89 & 156,1 & 29.000 & 33,2 & 1,8 & 0,03 & 0,42 & 0,42 & 162,2 & 390 & 88,3 & 1,3 & 0,0 & 0,4 & 0 & 214,6 & 0.000 \\
\hline & LT4 & 24,8 & 4,9 & 0,04 & 0,57 & 0,75 & & 3.000 & 22,9 & 4,7 & 0,04 & 0,55 & 7 & 3,3 & 260 & 55,2 & 1,4 & 0,0 &, 5 & 0 & 2 & \\
\hline & DT2 & 3,6 & 7,0 & 0,04 & 0,58 & 0,15 & 150,4 & 260 & 2,7 & 6,9 & 0,04 & 0,59 & 0,05 & 150,5 & 200 & 7,9 & 3,7 & 0,0 & 0,6 & 0,2 & 172,1 & 0 \\
\hline & DT5 & 4,5 & 7,7 & 0,04 & 0,58 & 0,39 & 150,1 & 900 & 3,5 & 7,9 & 0,04 & 0,58 & 0,05 & 150,1 & 210 & 10,7 & 5,4 & 0,0 & 0,6 & 4 & 55,2 & 0 \\
\hline \multirow{4}{*}{$\begin{array}{c}\text { Sông } \\
\text { Lòng Tàu }\end{array}$} & LT1 & 4,2 & 2,3 & 0,03 & 0,36 & 0,98 & 230,2 & 44.000 & 108,7 & 1,3 & 0,03 & 0,32 & 0,98 & 243,9 & 4.000 & 196,9 & 1,1 & 0,0 & 0,3 & 1,0 & 297,4 & 46.000 \\
\hline & LT2 & 15,9 & 2,8 & 0,03 & 0,37 & 0,97 & 211,7 & 35.000 & 94,8 & 1,9 & 0,03 & 0,38 & 0,87 & 226,7 & 1.600 & 171,1 & 1,2 & 0,0 & 0,3 & ,0 & 276,5 & 39.000 \\
\hline & LT6 & & 4,6 & & & & & & & 4,6 & & & & & & & 1,6 & 0 & & & & \\
\hline & LT7 & 2,2 & 5,5 & 0,04 & 0,45 & 0,09 & 137,2 & 290 & 2,2 & 5,5 & 0,04 & 0,45 & 0,03 & 137,9 & 200 & 4,2 & 4,1 & 0,0 & 0,5 & 0,1 & 152,3 & 300 \\
\hline \multirow{2}{*}{ S. Thị Vải } & TV1 & 2,4 & 5,4 & 0,05 & 0,57 & 0,02 & 158,8 & 340 & 2,5 & 5,4 & 0,05 & 0,57 & 0,02 & 157,9 & 340 & 2,4 & 5,1 & 0,1 & 0,5 & 0,0 & 156,4 & 50 \\
\hline & TV2 & & 5,4 & 0,05 & 0,46 & 0,02 & 154,6 & 260 & 2,2 & 5,4 & 0,05 & 0,46 & 0,02 & 154,7 & 260 & 2,2 & 5,1 & 0,0 & 0,5 & 0,0 & 153,7 & 280 \\
\hline \multirow{3}{*}{$\begin{array}{l}\text { Vịnh Đồng } \\
\text { Tranh }\end{array}$} & MR9 & 2,4 & 7,1 & 0,0 & 0,5 & 00 & 180,4 & 260 & 2,4 & 6,9 & 0,0 & 0,5 & 0,0 & 180,4 & 230 & 2,4 & 5,4 & 0,0 & 0,5 & 0 & 196,9 & 280 \\
\hline & MR12 & 2,3 & 6,7 & 0, & 0 & 0,0 & & & 2,3 & 6,7 & 0,0 & 0,5 & 0,0 & 173,5 & 200 & 6,1 & 5,1 & 0,0 & 0,5 & , 1 & 5,6 & 00 \\
\hline & MR13 & 3,4 & 6,9 & 0,0 & 0 & 0 & 141,4 & 53 & 2,0 & 7,2 & 0,0 & 0,3 & 0 , & 143,1 & 210 & 9,6 & 5,0 & 0,0 & 0,3 & 0,3 & 154,0 & 30 \\
\hline \multirow{4}{*}{$\begin{array}{l}\text { Vùng biển } \\
\text { Ven bờ }\end{array}$} & MR5 & 3,4 & 7,5 & 0,0 & 0,5 & 0,2 & 140,7 & & 1, & 7,7 & ,0 & 0,5 & 0,0 & 159,3 & 210 & 10,5 & 4,5 & 0,0 & 0,5 & 3 &, 4 & 0 \\
\hline & MR14 & 2,3 & 7,6 & 0,0 & 0,3 & 0,2 & 129,9 & & 1,3 & 7,9 & 0 & 0,3 & 0, & 160,3 & 200 & 11,3 & 5,3 & 0,0 & 0,3 & 0,3 & 179,7 & 0 \\
\hline & MR15 & 1,9 & 6,7 & 0,0 & 0,4 & 0,1 & 137,2 & 210 & 1,9 & 6,8 & 0,0 & 0,4 & 0,0 & 167,8 & 200 & 5,1 & 5,1 & 0,0 & 0,4 & 0,1 & 209,2 & 240 \\
\hline & MR7 & 2,3 & 5,8 & 0,0 & 0,5 & 0,0 & 153,6 & 240 & 2,3 & 5,8 & 0,0 & 0,5 & 0,0 & 173,5 & 220 & 2,3 & 5,3 & 0,0 & 0,5 & 0,0 & 195,9 & 260 \\
\hline \multirow{4}{*}{$\begin{array}{c}\text { Vịnh } \\
\text { Gành Rái }\end{array}$} & MR1 & 1,7 & 6,3 & 0,0 & 0,4 & 0,0 & 138,8 & 230 & 1,6 & 6,3 & 0,0 & 0,4 & 0,0 & 147,7 & 200 & 2,9 & 5,3 & 0,0 & 0,4 & 0,1 & 158,5 & 240 \\
\hline & MR2 & 1,9 & 5,9 & 0,0 & 0,4 & 0,0 & 139,2 & 260 & 1,8 & 6,0 & 0,0 & 0,4 & 0,0 & 140,9 & 240 & 2,7 & 5,3 & 0,0 & 0,4 & 0,1 & 145,7 & 280 \\
\hline & MR3 & 2,0 & 5,6 & 0,0 & 0,4 & 0,0 & 143,0 & 230 & 2,0 & 5,5 & 0,0 & 0,4 & 0,0 & 144,8 & 220 & 2,0 & 5,2 & 0,0 & 0,4 & 0,0 & 151,9 & 240 \\
\hline & MR4 & 2,3 & 5,7 & 0,0 & 0,5 & 0,1 & 136,9 & 430 & 1,7 & 5,8 & 0,0 & 0,5 & 0,0 & 139,3 & 210 & 3,8 & 4,5 & 0,0 & 0,5 & 0,1 & 143,3 & 440 \\
\hline
\end{tabular}


Bảng 7. Kết quả mô phỏng CLN vùng bờ đến 2030 theo các kịch bản XLNT và BĐKH (tiếp theo).

\begin{tabular}{|c|c|c|c|c|c|c|c|c|c|c|c|c|c|c|c|c|c|c|c|c|c|c|}
\hline \multirow{2}{*}{$\begin{array}{l}\text { KHU } \\
\text { Vực }\end{array}$} & \multirow{2}{*}{$\begin{array}{l}\text { VI! } \\
\text { TRÍ }\end{array}$} & \multicolumn{7}{|c|}{ KB4 - 2030} & \multicolumn{7}{|c|}{ KB5 - NĂM 2030} & \multicolumn{7}{|c|}{ KB6 - NĂM 2030} \\
\hline & & BOD & DO & $\mathrm{NH}_{4}^{+}$ & $\mathrm{NO}_{3}$ & $\mathrm{PO}_{4}{ }^{3}$ & TSS & Colif & BOD & DO & $\mathrm{NH}_{4}^{+} \mathrm{I}$ & $\mathrm{NO}_{3} \mathrm{P}$ & $\mathrm{PO}_{4}{ }^{3 .}$ & TSS & Coli & BOD & DO : & $\mathrm{NH}_{4}{ }^{+}$ & $\mathrm{NO}_{3}$ & $\mathrm{PO}_{4}{ }^{3 .}$ & TSS C & Colifor \\
\hline \multirow{3}{*}{$\begin{array}{l}\text { Sông } \\
\text { Soài Rạp }\end{array}$} & SR1 & 198,7 & 1,0 & 0,01 & 0,15 & 0,99 & 397,0 & 43.000 & 192,5 & 1,1 & 0,01 & 0,15 & 0,99 & 376,4 & 3.600 & 76,7 & 1,2 & 0,01 & 0,15 & 0,99 & 245,0 & 1.100 \\
\hline & SR3 & 129,7 & 3,3 & 0,04 & 0,60 & 0,69 & 325,9 & 29.000 & 105,7 & 4,2 & 0,04 & 0,60 & 0,68 & 306,4 & 440 & 42,4 & 5,1 & 0,04 & 0,60 & 0,67 & 246,9 & 320 \\
\hline & SR4 & 70,8 & 6,1 & 0,04 & 0,59 & 0,41 & 252,2 & 3.000 & 19,2 & 6,6 & 0,04 & 0,57 & 0,38 & 191,0 & 300 & 8,1 & 6,7 & 0,04 & 0,57 & 0,33 & 182,9 & 240 \\
\hline \multirow{3}{*}{$\begin{array}{l}\text { Sông } \\
\text { Vàm Sát }\end{array}$} & DT1 & 153,2 & 1,7 & 0,04 & 0,51 & 0,82 & 217,7 & 9.500 & 132,8 & 1,9 & 0,03 & 0,51 & 0,81 & 361,7 & 360 & 64,9 & 1,8 & 0,03 & 0,51 & 0,81 & 261,8 & 230 \\
\hline & DT3 & 33,1 & 6,2 & 0,04 & 0,59 & 0,20 & 212,8 & 260 & 23,8 & 6,6 & 0,04 & 0,59 & 0,19 & 189,0 & 210 & 9,9 & 6,8 & 0,04 & 0,59 & 0,19 & 151,4 & 200 \\
\hline & DT4 & 7,8 & 6,7 & 0,04 & 0,59 & 0,28 & 152,9 & 530 & 3,4 & 7,7 & 0,04 & 0,59 & 0,05 & 150,6 & 240 & 2,7 & 7,8 & 0,04 & 0,59 & 0,04 & 150,3 & 210 \\
\hline \multirow{4}{*}{$\begin{array}{l}\text { Sông } \\
\text { Đồng } \\
\text { Tranh }\end{array}$} & LT3 & 87,0 & 1,8 & 0,02 & & 0,98 & 212,6 & 28.000 & 48,5 & 2,2 & 0,03 & 0,35 & 0,42 & 170,2 & 460 & 11,7 & 3,5 & 0,03 & 0,35 & 0,42 & 152,3 & 440 \\
\hline & LT4 & 54,8 & 3,1 & 0,04 & 0,52 & 0,98 & 195,3 & 4.000 & 29,6 & 4,0 & 0,04 & 0,52 & 0,29 & 156,5 & 360 & 5,6 & 5,6 & 0,04 & 0,52 & 0,29 & 146,6 & 240 \\
\hline & DT2 & 7,3 & 6,4 & 0,04 & 0,58 & 0,20 & 170,6 & 340 & 5,0 & 6,7 & 0,04 & 0,58 & 0,05 & 150,7 & 240 & 4,4 & 6,8 & 0,04 & 0,58 & 0,05 & 150,4 & 210 \\
\hline & DT5 & 9,7 & 6,8 & 0,04 & 0,59 & 0,38 & 152,2 & 900 & 2,8 & 7,8 & 0,04 & 0,59 & 0,06 & 150,4 & 260 & 2,3 & 7,9 & 0,04 & 0,59 & 0,05 & 150,0 & 200 \\
\hline \multirow{4}{*}{$\begin{array}{c}\text { Sông } \\
\text { Lòng } \\
\text { Tàu }\end{array}$} & LT1 & 196,7 & 1,4 & 0,02 & 0,25 & 0,99 & 295,0 & 46.000 & 143,9 & 1,8 & 0,02 & 0,25 & 0,98 & 283,4 & 3.600 & 47,0 & 2,7 & 0,02 & 0,25 & 0,98 & 243,2 & 3.0 \\
\hline & LT2 & 162,7 & 1,7 & 0,03 & 0,33 & 0,99 & 274,3 & 36.000 & 120,7 & 2,1 & 0,03 & 0,33 & 0,85 & 250,1 & 1.400 & 36,6 & 3,9 & 0,03 & 0,33 & 0,84 & 236,8 & 900 \\
\hline & LT6 & 48,6 & 3,6 & 0,04 & 0,42 & 0,65 & 181,0 & 2.100 & 22,3 & 4,1 & 0,04 & 0,42 & 0,20 & 155,7 & 300 & 4,1 & 5,3 & 0,04 & 0,42 & 0,20 & 140,7 & 290 \\
\hline & LT7 & 4,0 & 4,9 & 0,04 & 0,45 & 0,11 & 150,3 & 500 & 2,9 & 5,2 & 0,04 & 0,45 & 0,04 & 138,3 & 240 & 1,5 & 5,7 & 0,04 & 0,45 & 0,04 & 129,8 & 3210 \\
\hline \multirow{2}{*}{$\begin{array}{l}\text { S. Thị } \\
\text { Vài }\end{array}$} & TV1 & 2,5 & 5,4 & 0,05 & 0,57 & 0,02 & 158,9 & 350 & 2,5 & 5,4 & 0,05 & 0,57 & 0,02 & 159,4 & 350 & 2,5 & 5,4 & 0,05 & 0,57 & 0,02 & 144,9 & 340 \\
\hline & TV2 & 2,2 & 5,4 & 0,05 & 0,46 & 0,02 & 154,8 & 340 & 2,2 & 5,4 & 0,05 & 0,46 & 0,02 & 157,4 & 300 & 2,2 & 5,4 & 0,05 & 0,46 & 0,02 & 137,5 & ; 270 \\
\hline \multirow{3}{*}{$\begin{array}{l}\text { Vinh } \\
\text { Đồng } \\
\text { Tranh }\end{array}$} & MR9 & 2,4 & 6,4 & 0,0 & 0,5 & 0,0 & 184,4 & 28 & 2,4 & 6,9 & 0,0 & 0,5 & 0,0 & 180,4 & 280 & 1,9 & 7,9 & 0,0 & 0,3 & 0,0 & 179,4 & 1 \\
\hline & MR12 & 5,8 & 5,8 & 0,0 & 0,5 & 0,1 & 171,5 & 300 & 2,3 & 6,6 & 0,0 & 0,5 & 0,0 & 161,7 & 240 & 1,6 & 6,3 & 0,0 & 0,4 & 0,0 & 153,8 & 210 \\
\hline & MR13 & 9,8 & 6,8 & 0,0 & 0,3 & 0,3 & 145,2 & 530 & 2,2 & 7,0 & 0,0 & 0,3 & 0,1 & 137,3 & 240 & 2,1 & 6,0 & 0,0 & 0,4 & 0,0 & 140,1 & 210 \\
\hline \multirow{4}{*}{$\begin{array}{c}\text { Vùng } \\
\text { biển } \\
\text { Ven bờ }\end{array}$} & MR5 & 9,6 & 5,6 & 0,0 & 0,5 & 0,3 & 153,5 & 260 & 2,3 & 7,6 & 0,0 & 0,5 & 0,1 & 159,3 & 240 & 2,3 & 5,8 & 0,0 & 0,5 & 0,0 & 138,5 & 210 \\
\hline & MR14 & 8,1 & 7,1 & 0,0 & 0,3 & 0,3 & 180,4 & 300 & 2,1 & 7,7 & 0,0 & 0,3 & 0,1 & 173,5 & 240 & 1,9 & 6,8 & 0,0 & 0,4 & 0,0 & 160,3 & 210 \\
\hline & MR15 & 4,7 & 6,7 & 0,0 & 0,4 & 0,1 & 198,8 & 290 & 1,9 & 6,7 & 0,0 & 0,4 & 0,0 & 176,7 & 240 & 2,4 & 5,9 & 0,0 & 0,5 & 0,0 & 167,8 & 3210 \\
\hline & MR7 & 2,3 & 6,3 & 0,0 & 0,5 & 0,0 & 183,5 & 260 & 2,3 & 5,8 & 0,0 & 0,5 & 0,0 & 180,3 & 280 & 2,3 & 6,7 & 0,0 & 0,5 & 0,0 & 173,5 & 200 \\
\hline \multirow{4}{*}{$\begin{array}{c}\text { Vịnh } \\
\text { Gành } \\
\text { Rái }\end{array}$} & MR1 & 2,8 & 5,8 & 0,0 & 0,4 & 0,1 & 145,6 & 240 & 1,6 & 6,3 & 0,0 & 0,4 & 0,0 & 147,7 & 240 & 2,0 & 5,5 & 0,0 & 0,4 & 0,0 & 133,8 & 210 \\
\hline & MR2 & 2,6 & 6,6 & 0,0 & 0,4 & 0,1 & 140,1 & 290 & 1,8 & 6,0 & 0,0 & 0,4 & 0,0 & 140,9 & 280 & 1,7 & 5,9 & 0,0 & 0,5 & 0,0 & 130,1 & 230 \\
\hline & MR3 & 2,0 & 7,0 & 0,0 & 0,4 & 0,0 & 143,9 & 300 & 2,0 & 5,5 & 0,0 & 0,4 & 0,0 & 144,8 & 290 & 1,8 & 7,8 & 0,0 & 0,5 & 0,1 & 132,9 & 230 \\
\hline & MR4 & 3,9 & 5,9 & 0,0 & 0,5 & 0,1 & 137,4 & 460 & 1,9 & 5,7 & 0,0 & 0,5 & 0,0 & 139,3 & 300 & 1,9 & 7,9 & 0,0 & 0,3 & 0,0 & 127,0 & 260 \\
\hline
\end{tabular}

Bảng 8. Chỉ số CLN (CCME) vùng bờ TpHCM đến năm 2030 trên cơ sở 07 thông số mô phỏng.

\begin{tabular}{|c|c|c|c|c|c|c|c|c|c|c|c|c|c|}
\hline \multirow{2}{*}{ Khu vụ̣c } & \multirow{2}{*}{ Vị trí } & \multirow{2}{*}{$\begin{array}{l}2019 \\
\text { KB1 }\end{array}$} & \multicolumn{5}{|c|}{ NĂM 2025} & \multicolumn{6}{|c|}{ NĂM 2030} \\
\hline & & & KB2 & KB3 & KB7 & KB8 & KB9 & KB10 & KB4 & KB5 & KB6 & KB11 & KB12 \\
\hline \multirow{3}{*}{$\begin{array}{c}\text { Sông } \\
\text { Soài Rạp }\end{array}$} & SR1 & 26 & 26 & 26 & 74 & 30 & 42 & 25 & 25 & 28 & 40 & 25 & 25 \\
\hline & SR3 & 42 & 42 & 41 & 77 & 52 & 54 & 28 & 28 & 49 & 54 & 27 & 26 \\
\hline & SR4 & 47 & 45 & 45 & 79 & 70 & 81 & 41 & 41 & 60 & 70 & 36 & 33 \\
\hline \multirow{3}{*}{$\begin{array}{c}\text { Sông } \\
\text { Vàm Sát }\end{array}$} & DT1 & 80 & 55 & 54 & 79 & 41 & 60 & 29 & 29 & 38 & 45 & 28 & 27 \\
\hline & DT3 & 82 & 81 & 81 & 83 & 82 & 83 & 67 & 67 & 70 & 82 & 56 & 50 \\
\hline & DT4 & 82 & 81 & 81 & 83 & 82 & 83 & 81 & 82 & 83 & 83 & 82 & 74 \\
\hline \multirow{4}{*}{$\begin{array}{l}\text { Sông } \\
\text { Đồng } \\
\text { Tranh }\end{array}$} & LT3 & 33 & 31 & 31 & 85 & 47 & 74 & 29 & 29 & 46 & 61 & 29 & 28 \\
\hline & LT4 & 59 & 59 & 59 & 83 & 72 & 83 & 43 & 43 & 70 & 82 & 42 & 40 \\
\hline & DT2 & 82 & 81 & 81 & 83 & 82 & 83 & 81 & 81 & 82 & 82 & 72 & 72 \\
\hline & DT5 & 72 & 72 & 72 & 83 & 82 & 83 & 72 & 72 & 83 & 83 & 72 & 70 \\
\hline \multirow{4}{*}{$\begin{array}{c}\text { Sông } \\
\text { Lòng Tàu }\end{array}$} & LT1 & 27 & 27 & 27 & 87 & 39 & 43 & 26 & 26 & 38 & 43 & 25 & 21 \\
\hline & LT2 & 28 & 28 & 28 & 85 & 41 & 58 & 27 & 27 & 39 & 45 & 26 & 23 \\
\hline & LT6 & 60 & 60 & 60 & 83 & 73 & 84 & 45 & 45 & 71 & 83 & 44 & 42 \\
\hline & LT7 & 83 & 82 & 82 & 83 & 83 & 83 & 82 & 82 & 83 & 84 & 82 & 70 \\
\hline \multirow{2}{*}{$\begin{array}{l}\text { Sông } \\
\text { Thị Vải }\end{array}$} & TV1 & 82 & 82 & 82 & 82 & 82 & 82 & 82 & 82 & 82 & 82 & 82 & 82 \\
\hline & TV2 & 82 & 82 & 82 & 82 & 82 & 82 & 82 & 82 & 82 & 82 & 82 & 82 \\
\hline \multirow{3}{*}{$\begin{array}{l}\text { Vịnh } \\
\text { Đồng } \\
\text { Tranh }\end{array}$} & MR9 & 80 & 80 & 80 & 84 & 81 & 81 & 79 & 79 & 81 & 84 & 79 & 79 \\
\hline & MR12 & 81 & 81 & 81 & 84 & 81 & 84 & 81 & 81 & 81 & 84 & 80 & 80 \\
\hline & MR13 & 72 & 70 & 70 & 84 & 83 & 83 & 72 & 72 & 83 & 83 & 72 & 70 \\
\hline \multirow{4}{*}{$\begin{array}{c}\text { Vùng } \\
\text { biển ven } \\
\text { bờ }\end{array}$} & MR5 & 78 & 76 & 76 & 84 & 84 & 84 & 71 & 71 & 84 & 84 & 70 & 67 \\
\hline & MR14 & 80 & 74 & 74 & 84 & 84 & 84 & 70 & 70 & 84 & 84 & 70 & 70 \\
\hline & MR15 & 81 & 80 & 80 & 84 & 83 & 84 & 79 & 79 & 84 & 84 & 78 & 74 \\
\hline & MR7 & 81 & 81 & 81 & 84 & 81 & 81 & 80 & 80 & 81 & 81 & 79 & 78 \\
\hline \multirow{4}{*}{$\begin{array}{c}\text { Vịnh } \\
\text { Gành Rái }\end{array}$} & MR1 & 83 & 82 & 82 & 84 & 83 & 84 & 82 & 82 & 84 & 84 & 82 & 80 \\
\hline & MR2 & 83 & 82 & 82 & 84 & 83 & 84 & 83 & 83 & 83 & 84 & 83 & 80 \\
\hline & MR3 & 83 & 82 & 82 & 84 & 83 & 84 & 83 & 83 & 83 & 84 & 82 & 80 \\
\hline & MR4 & 83 & 82 & 82 & 84 & 84 & 84 & 72 & 73 & 84 & 84 & 73 & 70 \\
\hline
\end{tabular}



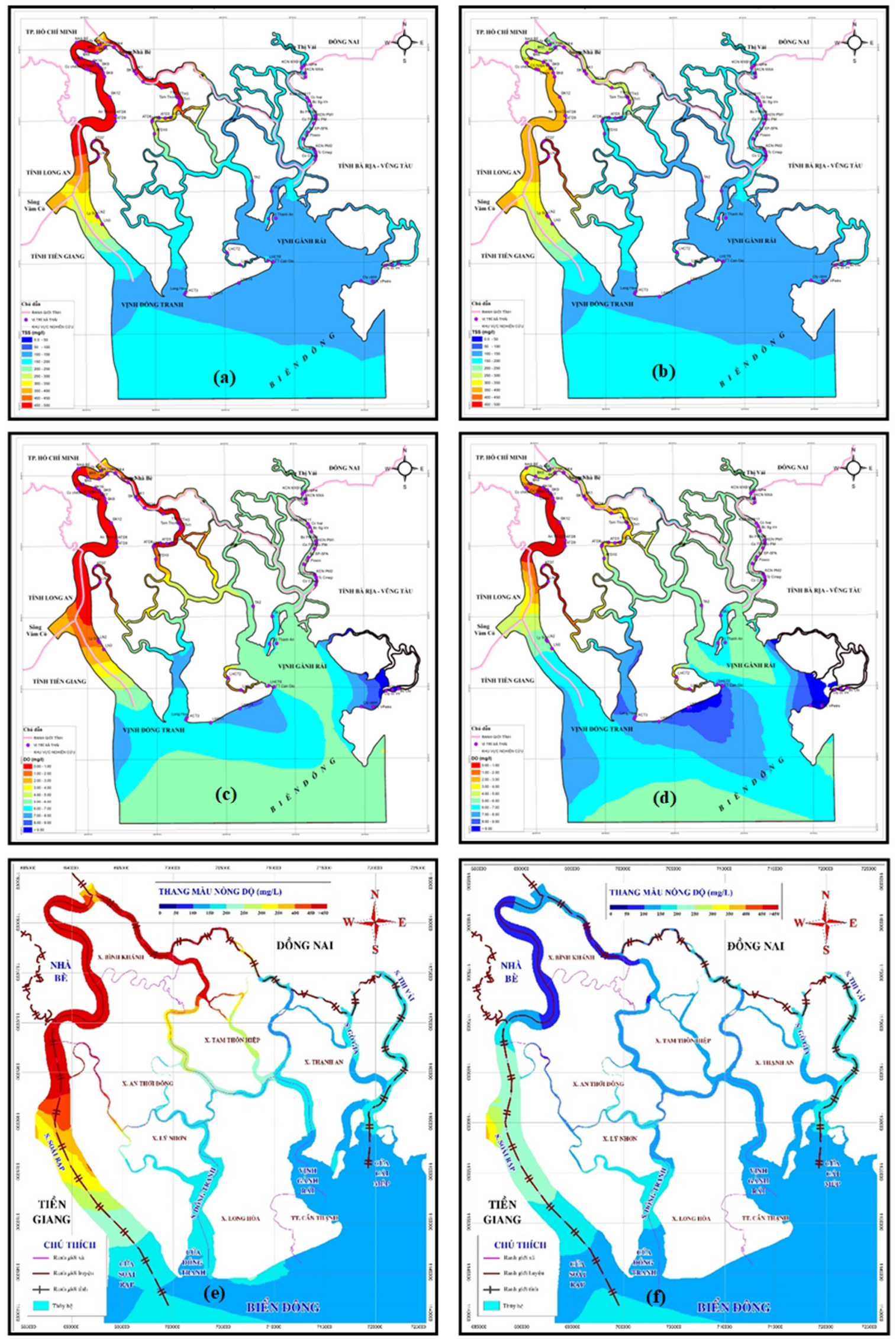

Hình 7. Biến đổi nồng độ một số thông số CLN tại vùng bờ TpHCM giai đoạn 2019-2030: $(\mathrm{a}, \mathrm{b})$ Coliform: XLNT đáp ứng quy chuẩn (KB1 và $K B 5)$; $(\mathrm{c}, \mathrm{d}) \mathrm{DO}$ : XLNT đáp ứng tối đa quy chuẩn (KB1 và $K B 6)$; (e, f) TSS: có và không có nguồn thải nội vi (KB3 và $K B 7)$. 
Có thể thấy rằng, ngay cả xử lý tối ưu nước thải nội vi vùng bờ TpHCM, các nguồn tiếp nhận chủ yếu trong lục địa (sông Soài Rạp, Lòng Tàu) vẫn tiềm tàng nguy cơ ô nhiễm, nhất là khu vực thượng lưu, xa cửa sông, không có lợi thế khuếch tán và pha loãng chất ô nhiễm. Theo đó, quy hoạch nguồn thải nội vi và tăng cường kiểm soát CLN ngoại vi là một trong những giải pháp quan trọng nhằm quản lý hiệu quả môi trường nước mặt vùng bờ TpHCM trong bối cảnh phát triển không ngừng kinh tế-xã hội dọc lưu vực sông Sài Gòn-Đồng Nai.

\section{Kết luận}

CLN vùng bờ TpHCM được mô phỏng đến năm 2030 với 7 thông số $\left(\mathrm{BOD}, \mathrm{DO}, \mathrm{NO}_{3}{ }^{-}-\mathrm{N}\right.$, $\mathrm{NH}_{4}{ }^{+}-\mathrm{N}, \mathrm{PO}_{4}{ }^{3-}-\mathrm{P}$, TSS và Coliform), xem xét các kịch bản khác nhau về XLNT và $\mathrm{NBD}(\mathrm{RCP} 4.5$ và $\mathrm{RCP} 8.5$ ). Giai đoạn 2019-2030, nếu không cải thiện tình hình XLNT, CLN vùng bờ nhất là khu vực lục địa sẽ suy giảm, dao động ở mức kém-khá, nồng độ TSS, $\mathrm{BOD}$ và $\mathrm{PO}_{4}$ tương đương 3-8, $3-13$ và 2-3 lần quy chuẩn. Trong trường hợp đáp ứng hoặc đáp ứng tối đa các quy định về XLNT, CLN vùng bờ chuyển biến tích cực trong giai đoạn 2020-2025 (BOD và $\mathrm{PO}_{4}^{3-}-\mathrm{P}$ ), nhưng giảm dần đến năm 2030 do gia tăng xả thải từ các hoạt động KTXH. Cần lưu ý rằng, ngay cả đáp ứng tối đa về XLNT, nước mặt lục địa vẫn có nguy cơ ô nhiễm (thượng nguồn các sông Soài Rạp, Lòng Tàu, Vàm Sát). Nghiên cứu cũng chỉ ra nguồn thải nội vi đóng góp đáng kể $\mathrm{BOD}$ và $\mathrm{PO}_{4}{ }^{3-}-\mathrm{P}$ vào CLN vùng bò̀. Bên cạnh đó, các RCP khác nhau ảnh hưởng khá tương đồng đến CLN tại cùng mốc thời gian tính toán, do vậy có thể chỉ nên xem xét 1 kịch bản RCP trong mô phỏng CLN ở tương lai gần (đến 2030).

Đóng góp của tác giả: Xây dựng ý tưởng nghiên cứu, Viết bản thảo bài báo, Chỉnh sửa bài báo: L.N.T.; Lựa chọn phương pháp nghiên cứu, Xử lý số liệu: T.T.H.; Lấy mẫu, Phân tích mẫu: IMHOEN.

Lời cảm ơn: Nghiên cứu này được tài trợ bởi Sở Khoa học và Công nghệ thành phố Hồ Chí Minh trong khuôn khổ Nhiệm vụ nghiên cứu KH\&CN "Đánh giá khả năng chịu tải của vịnh Đồng Tranh, vịnh Gành Rái và cửa sông Soài Rạp trước sức ép của sự gia tăng dân số và tăng trưởng kinh tế của vùng hạ lưu hệ thống sông Đồng Nai”.

Lời cam đoan: Tập thể tác giả cam đoan bài báo này là công trình nghiên cứu của tập thể tác giả, chưa được công bố ở đâu, không được sao chép từ những nghiên cứu trước đây; không có sự tranh chấp lợi ích trong nhóm tác giả.

\section{Tài liệu tham khảo}

1. Meybeck, M.; Kuusisto, E.; Mäkelä, A.; Mälkki, E. Water Quality Monitoring - A Practical Guide to the Design and Implementation of Freshwater Quality Studies and Monitoring Programmes, UNEP/WHO, 1996.

2. Toro, D.; D.M.; Fitzpatrick, J.J.; Thomann, R.V. Water Quality Analysis Simulation Program (WASP) and Model Verification Program (MVP), Hydroscience, Inc., Westwood, NY, for U.S. EPA, Duluth, MN, 1983.

3. Ambrose, R.B.; Connolly, J.P.; Schanz, R.W. WASP4, A Hydrodynamic and Water Quality Model-Model Theory, User's Manual, and Programmer's Guide. U.S. Environmental Protection Agency, Athens, GA. EPA/600/3-87-039, 1988.

4. Tình, T.T.; Hải, Đ.N.; Hà, B.N.L.; Thuận, N.T.T. Đánh giá mức độ ảnh hưởng của các nguồn nước chảy vào hồ Đan Kia và áp dụng mô hình AQUATOX quản lý chất lượng nước hồ. Tạp chí sinh học đại học Đà Lạt 2015, 38, 61-69.

5. Trang, C.T.T.; An, P.H.; Tú, T.A.; Cường, L.Đ.; Thạnh, T.Đ.; Thành, T. Mô phỏng lan truyền chất ô nhiễm khu vực Phá Tam Giang - Cầu Hai, Thừa Thiên - Huế bằng mô hình DELFT-3D. Tạp chi Khoa họ và Công nghệ Biển 2014, 3, 272-279.

6. Chính, P.V. Ửng dụng mô hình toán đánh giá chất lượng nước hạ lưu sông Đồng Nai đến năm 2020. Tạp chí nghiên cưu khoa học trương đại học Đông Á 2011, 4, 40-53. 
7. Thắng, N.T.; Thái, T.H.; Hương, Đ.T.; Dũng, L.Đ. Dự báo diễn biến chất lượng nước sông Nhuệ - Đáy theo các kịch bản phát triển kinh tế-xã hội. Tạp chí Khoa học Đại học Quốc gia Hà Nọi 2013, 2S, 166-276.

8. Bhargava, D.S. Use of water quality index for river classification and zoning of Ganga River. Environ. Pollut. Ser. B. England 1983, 6, 51-67.

9. Sutadian, A.D.; Muttil, N.; Yilmaz, A.; Perera, C. Development of River Water Quality Indices - A Review. Environ. Monit. Assess. 2016, 58, 1-33.

10. Tuấn, L.N.; Quân, T.M.; Thuý, T.T. Áp dụng chỉ số chất lượng nước đánh giá diễn biến chất lượng nước mặt tại khu vực phía Nam tỉnh Bình Dương. Tạp chí Phát triển Khoa hoc \& Công nghệ 2018, 6, 118-127.

11. Quân, T.M. Điều tra, đánh giá khả năng chịu tải và đề xuất các giải pháp giảm thiểu ô nhiễm trên kênh, rạch cho vùng đô thị phía Nam tỉnh Bình Dương. Sở Khoa học và Công nghệ tỉnh Bình Dương, 2018.

12. Thái, N.Đ. Nghiên cứu biến động môi trường trầm tích trong Holocen muộn phục vụ quy hoạch phát triển bền vững khu vực cửa sông Đồng Nai. Trường Đại học Khoa học tự nhiên-Đại học Quốc gia Hà Nội, 2015.

13. Phùng, N.K.; Tín, N.V.; Tuẩn, L.N. Xây dựng kịch bản biến đổi nhiệt độ trong bối cảnh biến đổi khí hậu cho khu vực thành phố Hồ Chí Minh. Hội thảo Khoa học Quốc tế "Toàn cầu hóa, biến đổi khí hậu và phát triển bền vững”, 09/05/2017, Trường Đại học Hà Tĩnh, Hà Tĩnh, 2017.

14. Tuấn, L.N.; Thịnh, N.N.; Phùng, N.K. Xây dựng kịch bản mực nước biển dâng trong bối cảnh biến đổi khí hậu cho khu vực thành phố Hồ Chí Minh. Tap chí Phát triển Khoa họ và Công nghệ 2018, 5, 184-191.

15. Phung, N.K.; Tin, N.V.; Tuan, L.N. Precipitation scenarios in Ho Chi Minh city in the context of climate change. VJST 2017, 4C, 115-121.

\section{Forecasting surface water quality in the coastal area in Ho Chi Minh City to 2030 in the context of sea level rise}

\section{Le Ngoc Tuan ${ }^{*}$, Tran Tuan Hoang ${ }^{2}$}

${ }^{1}$ Vietnam National of Ho Chi Minh City-University of Science; lntuan@hcmus.edu.vn

${ }^{2}$ Sub-Institute Of Hydrometeorology and Climate Change; hoangkttv@gmail.com

Abstract: The study aimed to assess water quality in the coastal area of Ho Chi Minh City to 2030 (via parameters of BOD, $\mathrm{DO}, \mathrm{NO}_{3}{ }^{-}-\mathrm{N}, \mathrm{NH}_{4}{ }^{+}-\mathrm{N}, \mathrm{PO}_{4}{ }^{3-}-\mathrm{P}$, TSS, and Coliform) in the context of sea level rise (RCP4.5 and RCP8.5) under different wastewater treatment scenarios. In the period of 2019-2030, if the wastewater treatment situation is not improved, areas (and related parameters) of concern would be Soai Rap, Long Tau, Vam Sat rivers (TSS, BOD, $\mathrm{PO}_{4}{ }^{3-}-\mathrm{P}$ ), and the coastal area of Long Hoa-Can Thanh (TSS, $\mathrm{PO}_{4}{ }^{3-}-\mathrm{P}$ ). In case of meeting or maximal meeting the regulations on wastewater quality, the coastal water quality would positively change (BOD and $\mathrm{PO}_{4}{ }^{3-}-\mathrm{P}$ ) in the period 2020-2025, but gradually decrease in the following years due to the increase in discharge from economic activities. It should be noted that, even maximal meeting the regulations on wastewater treatment, continental (upstream) surface water would be still polluted in 2030 by BOD, $\mathrm{PO}_{4}{ }^{3-}-\mathrm{P}$, and TSS (about 2-5 times as many as the standard). Results showed wastewater generators in the research areas have significantly contributed $\mathrm{BOD}$ and $\mathrm{PO}_{4}{ }^{3-}-\mathrm{P}$ into the coastal water. It is also recommended to reduce the number of RCP scenarios when simulating water quality in the near future due to small differences among caculating results.

Keywords: Coastal area; Surface water; Water quality; Water quality index. 